\title{
HDQLIFE and Neuro-QoL Physical Function measures: Responsiveness in persons with Huntington disease
}

\author{
Noelle E. Carlozzi, PhD,${ }^{1}$ Nicholas R. Boileau, MPH,${ }^{1}$ Kelvin L. Chou, $\mathrm{MD}^{2}$, Rebecca E. Ready, \\ PhD., ${ }^{3}$ David Cella, PhD, ${ }^{4}$ Michael K McCormack, PhD,${ }^{5}$ Jennifer A. Miner, MBA, ${ }^{1} \&$ \\ Praveen, Dayalu, $\mathrm{MD}^{2}$
}

Word Count: 4352

${ }^{1}$ Department of Physical Medicine and Rehabilitation, University of Michigan, Ann Arbor, MI, USA

${ }^{2}$ Department of Neurology, University of Michigan, Ann Arbor, MI, USA

${ }^{3}$ Department of Psychological and Brain Sciences, University of Massachusetts, Amherst, MA, USA

${ }^{4}$ Department of Medical Social Sciences, Northwestern University Feinberg School of Medicine, Chicago, IL, USA

${ }^{5}$ Department of Psychiatry, Rutgers University-Robert Wood Johnson Medical School, Piscataway, NJ and Department of Pathology, Rowan University-SOM, Stratford, NJ

This is the author manuscript accepted for publication and has undergone full peer review but has not been through the copyediting, typesetting, pagination and proofreading process, which may lead to differences between this version and the Version of Record. Please cite this article as doi: $10.1002 / \mathrm{mds} .27908$

This article is protected by copyright. All rights reserved. 


\begin{abstract}
Background: Huntington disease (HD) is a neurological disorder that causes severe motor symptoms that adversely impact health-related quality of life. Patient reported physical function outcome measures in HD have shown cross-sectional evidence of validity, but responsiveness has not yet been assessed.

Objectives: This study evaluates the responsiveness of the Huntington Disease Health-Related Quality of Life (HDQLIFE) and the Quality of Life in Neurological Disorders (Neuro-QoL) physical function measures in persons with HD.

Methods: Three-hundred and forty-seven participants completed baseline and at least one follow-up (12- and 24-month) measure (HDQLIFE Chorea, HDQLIFE Swallowing Difficulties, HDQLIFE Speech Difficulties, Neuro-QoL Upper Extremity Function, and/or Neuro-QoL Lower Extremity Function). Of participants that completed the baseline assessment, 338 (90.9\%) completed the 12-month, and 293 (78.8\%) completed the 24-month assessments. Standardized response means and general linear models evaluated whether the physical function measures were responsive to self-reported and clinician-rated change over time.

Results: Small to moderate effect sizes for standardized response means supported 12 and 24month responsiveness of the HDQLIFE and Neuro-QoL measures for those with either selfreported or clinician-rated declines in function. General linear models supported 12- and 24month responsiveness for all HRQOL measures relative to self-reported declines in health, but generally only 24-month responsiveness was supported relative to clinician-rated declines in function.
\end{abstract}

This article is protected by copyright. All rights reserved. 
Conclusions: Longitudinal analyses indicate that the HDQLIFE and the Neuro-QoL physical function measures are sensitive to change over time in individuals with HD. Thus, these scales exhibit evidence of responsiveness and may be useful outcome measures in future clinical trials.

Keywords: health-related quality of life, Huntington's disease, patient reported outcome (PRO), psychometric, validity

This article is protected by copyright. All rights reserved. 


\section{Introduction}

Huntington disease (HD) is a progressive neurodegenerative disorder that causes profound cognitive, behavioral, and motor decline..$^{1-6}$ The motor disorder in HD is multifaceted and can include chorea, bradykinesia, rigidity, and dystonia; these symptoms adversely impact all body segments and limbs, with significant impact on daily living and social participation. ${ }^{7}$ In HD clinical trials, most motor outcomes are administered by clinicians (e.g., UHDRS Total Motor Score) but these measures correlate poorly with real-world function. ${ }^{8}$ Patient-reported outcome (PRO) measures of motor symptoms and associated functional limitations are rarely used in $\mathrm{HD}$, even though such outcomes are key measures of efficacy for new treatments. ${ }^{9}$ In HD, where many therapies under development seek to slow the loss of function related to motor problems, ${ }^{10-15}$ there is need for meaningful and sensitive PRO measures that capture physical aspects of health-related quality of life (HRQOL).

The Huntington Disease Health-Related Quality of Life (HDQLIFE) measurement system ${ }^{16-18}$ was designed to provide reliable and valid assessments of HRQOL in persons with HD. This system includes several HD-specific measures of HRQOL as well as generic HRQOL measures from the Quality of Life in Neurological Disorders (Neuro-QoL) system. ${ }^{19,20}$ In a large cross sectional study of persons affected with prodromal/premanifest, early-, and late-stage HD, the HDQLIFE physical function PROs demonstrated strong validity and reliability; ${ }^{21}$ however, responsiveness over time has not yet been established. It is essential to determine the efficacy of experimental treatments, responsiveness, or the ability of a measure to detect meaningful change. ${ }^{22}$ In the current study, we follow the same population out for two years to determine whether these PROs can detect change over time. We hypothesized that the HDQLIFE and 
Neuro-QoL measures would be responsive to self-reported global changes and clinician-rated changes in health. Specifically, we hypothesized that: 1) 12- and 24-month change would be greater in magnitude for those with self or clinician-rated declines in health relative to those reporting no change/improved health ; 2) there would be small to moderate 12- and 24-month effect sizes for participants with declines in health (based on either self-report or clinician ratings), negligible effect sizes for the group reporting no change, and negligible or small effect sizes for the group reporting improvements in physical health; and 3) there would be significant declines in PRO reports of physical HRQOL over time (for those individuals with self-reported declines or clinician-rated declines), whereas participants with no change or improvement in physical health would have no change, or no change/small improvements, respectively.

\section{Method}

\section{Study Participants}

Data were collected through the HDQLIFE study, a longitudinal study examining HRQOL in persons affected with HD. ${ }^{17}$ Participants were included in analyses if they completed at least one follow-up visit ( $n=372$ participants). A detailed description of the broader cohort study sample and recruitment methods are reported elsewhere. ${ }^{17}$ Study eligibility included a positive gene test and/or a clinical diagnosis of HD, as well as participant age of $\geq 18$ years, and ability to provide informed consent (cognitive status was confirmed using a standard assessment ${ }^{23}$ ). Study Procedures

Participants completed assessments at baseline and at 12- and 24-months. Each visit involved an in-person assessment and several computer-based self-report surveys regarding HRQOL, which could be completed during the in-person visit or at home. A subsample of 
participants $(n=24)$ participated in a 1 to 3 day retest of the self-report measures. All data were procured in accordance with the local institutional review boards, and participants provided informed consent prior to participation in this study.

\section{Measures}

Clinician-Rated Assessments. All clinician-rated assessments were completed at each study visit. The Unified Huntington Disease Rating Scale (UHDRS) ${ }^{24}$ was used to classify participants in this study. The final question on the UHDRS Total Motor Scale asks the rater to score a diagnostic confidence level (DCL) for the participant, on a scale of 0 (Normal) to 4 (symptoms unequivocal of HD with $>99 \%$ certainty), to determine whether the participant has motor symptoms consistent with manifest HD. If the participant scored less than a 4, they were rated as having premanifest HD. Participants whom opted to complete follow-up visits by telephone ( $-15 \%$ of the study sample), did not complete the Total Motor Scale at follow-up. The UHDRS Total Functional Capacity (TFC) scale was used to determine stage for manifest HD participants. TFC scores range from 0-13, with higher scores indicating better function. Participants scoring between 7-13 on the TFC were classified as early-HD while those scoring between 0-6 rated were classified as late-HD. ${ }^{7,25}$ Baseline data was used to determine HD staging data for all analyses.

The TFC was also used to characterize clinician-rated longitudinal change. Baseline TFC scores were subtracted from 12-month and 24-month scores, respectively to generate clinician- rated change scores in functioning for baseline to 12 months $(M=-0.44 ; S D=1.49)$ and baseline to 24 months $(M=-0.57 ; S D=2.07)$. The distribution of change scores were used to classify participants into three groups: those with declines in functioning (i.e., TFC scores that 
got worse at follow-up 1 SD greater than the sample; e.g., <-1.93 from baseline to 12-months and $<-2.63$ from baseline to 24-months), those with no change in functioning, or those with improvements in functioning (i.e., TFC scores that improved at follow-up 1 SD greater than the sample; e.g., >1.05 from baseline to 12 -months and >1.50 from baseline to 24-months). This resulted in $n=69$ participants with declines, $n=238$ with no change, and $n=23$ with improvements in clinician ratings for baseline to 12 -months, as well as $n=45$ participants with declines, $n=216$ with no change and $\mathrm{n}=28$ with improvements in clinician ratings for baseline to 24 -months.

Self-Reported Assessments. Participants provided information about age, gender, marital status, race, and ethnicity. Additionally, medical record data were used to confirm HD diagnosis and CAG repeat length for study participants.

Physical HRQOL was assessed using physical health measures from the HDQLIFE ${ }^{16-18}$ and Neuro-QoL measurement systems. Specifically, we examined HDQLIFE Chorea ${ }^{26}$ (which assesses the impact that chorea has on physical activity and participation), HDQLIFE Speech Difficulties $^{27}$ (which assesses how difficulty with speech--i.e., oral expression, language production, and articulation affects communication and well-being), HDQLIFE Swallowing Difficulties $^{27}$ (which assesses how problems with swallowing and choking impacts well-being and eating), Neuro-QoL Upper Extremity Function (which measures fine motor tasks and activities of daily living), and Neuro-QoL Lower Extremity Function (which measures mobility). The administration format for the HDQLIFE measures changed over the course of the study. Specifically, for the 259 participants (69.6\% of the overall sample) completing all three study visits, 112 (43.2\%) completed the full item pools for each HDQLIFE measure (64 items for Chorea, 27 items for Speech Difficulties, and 20 item for Swallowing Difficulties) and 147 
(56.8\%) completed the full item pools at the baseline and 12-months, but switched to answering assessments as computer adaptive tests (CATs) plus short forms (SFs) at their 24-month visit. Of the 79 participants that only completed the baseline and 12-month assessments (but not the 24-month assessment), all completed the full item pools. Finally, of the 34 participants that only completed the baseline and 24-month assessments, $11(32.4 \%)$ completed the full item pools at both assessments and $23(67.6 \%)$ switched to the CATs plus SFs administration at their 24month visit. All Neuro-QoL measures were administered as a CAT plus SF at each time point. All HDQLIFE and Neuro-QoL scores are on a T-metric $(M=50, S D=10)$; higher scores indicate more of the construct being assessed (i.e., high scores for HDQLIFE measures indicate worse physical HRQOL, whereas high scores on Neuro-QoL measures indicate better physical HRQOL). CAT scores were simulated for participants that completed the full item pools (rather than CAT administrations) using Firestar software. ${ }^{28}$ The CAT and SF administration of these measures takes one minute or less to complete. ${ }^{29}$

At each follow-up visit (i.e., 12- and 24-months), participants rated 5 anchor items (one for each of the 3 HDQLIFE and 2 Neuro-QoL measures) on a 5-point Likert scale, ranging from 1 (much worse) to 5 (much better), based on how they felt their condition was compared to the prior visit (Supplemental Table A). Each anchor item asked the participant about changes in either their chorea, speech, swallowing, ability to move their hands (i.e., upper extremities), or overall physical functioning (i.e., lower extremities). Based on their responses to each anchor item, participants were placed in three groups. Individuals who responded 1 (much worse) or 2 (worse) were included in the group with self-reported declines in health. Participants who responded 3 (same) were included in the group with no changes in health. Participants who 
responded 4 (better) or 5 (much better) were included in the group with improvements in health. To examine change from baseline to 24-month (for which there was no specific anchor), we classified participants who reported poorer function during any of the visits in the poorer selfreported health group, those who did not report any changes between visits into the selfreported no change group, and participants who reported improved functioning during any of the visits were placed in the self-reported improvement group. In the case that a participant reported improvement at one follow-up visit and decline in another, the ratings were offset and the participants was placed in the no change group.

\section{Statistical Analysis}

Descriptive Data. Statistical analyses were performed using SAS 9.4 software. ${ }^{30}$ The data were normally distributed (according to Bulmer's criteria) ${ }^{31}$ and therefore we used parametric tests to analyze the data. Group differences for demographic variables were examined using either chi-square (for categorical data; Fisher's Exact tests when cells counts < 5) or one-way analysis of variance (ANOVA; for continuous data). Descriptive data for each HRQOL measure were calculated for each HD group (premanifest, early-HD, late-HD). Oneway ANOVA with Bonferroni post-hoc analyses determined whether the 3 HD groups differed on the 5 HRQOL physical health measures at each of the three assessments (baseline 12-, and 24-months). We expected that the premanifest group would reported better physical HRQOL than the Early-HD group, who in turn would report better physical HRQOL than the Late-HD group.

Reliability and Measurement Error. Intraclass correlation coefficients (ICC; random twoway consistency model) were calculated to examine 1 to 3 day test-retest reliability for the small 
subsample of participants; 95\% confidence intervals (Cl) were calculated for each reliability coefficient. Minimum acceptable criteria for test-retest reliability was set at $\geq 0.70$ for intraclass correlations. $^{32}$

In addition, minimal important difference (MID), detectable change (DC95), and standard error of measurement (SEM) were calculated for the HDQLIFE and Neuro-QoL physical function measures. MID, or the smallest score change that are perceived as being important, ${ }^{33,34}$ were calculated using the means and standard deviations of participants who indicated that their physical function was either "a little worse," or "a little better" from baseline to 12-months (the absence of an anchor item to assess change from baseline to 24 months precluded the calculation of MIDs for this time frame). One-way ANOVA with Bonferonni post-hoc comparisons were used to determine if group differences were significant. $\mathrm{DC}_{95}$ was calculated as a conservative estimate and identify reliable change scores (i.e., the amount of change due that can be detected with $95 \%$ confidence as not due to measurement error) from baseline to 12-months. $\mathrm{DC}_{95}$ was calculated according to the following formula: ${ }^{35}$

$$
D C_{95}=S E M * 1.96 * \sqrt{2} .
$$

Finally, SEMs were calculated to estimate the maximum difference between one's observed score and their true score for a given assessment. ${ }^{36}$ SEM was calculated using the baseline data as follows:

$$
S E M=S D * \sqrt{1-I C C}
$$

where SD is the standard deviation of the sample and ICC is the test-retest reliability of the measure. SEM percentages (SEM divided by the mean of all observations across time-points times one-hundred) $<10 \%$ are indicative of good measurement error. ${ }^{37}$ 
Responsiveness. Guyatt's Responsiveness Statistic (RS) and Standardized Response Mean (SRM) effect sizes were calculated to examine the responsiveness of the HRQOL measures. RS were calculated by dividing the mean change of each group by the standard deviation of change in the "no change" group. ${ }^{38} \mathrm{RS}$ were calculated relative to self-reported and clinician-rated changes in physical health. SRMs were calculated by dividing the average change from baseline to follow-up (12- and 24-month) by the standard deviation of the change. ${ }^{39,40}$ SRMs were also calculated relative to self-reported and clinician-rated changes in physical health. For self-reported changes in health, we compared participants with selfreported declines in health to those with no change and those with improvements in health. For clinician-rated changes in health we compared participants with clinician-rated declines in function relative those with no change or those with improvements in clinician-rated function. Given findings in other clinical samples, ${ }^{41}$ we hypothesized that RS and SRM effect sizes would be greater in magnitude for those who reported (or with clinician-rated) declines in health relative to those reporting no change/improved health. Effect sizes between 0.00 and $|0.19|$ were considered "negligible", $|0.20|$ to $|0.49|$ were small, $|0.50|$ to $|0.79|$ were moderate, and $\geq$ $|0.80|$ were large.$^{39}$ We hypothesized that participants who reported declines in health would have effect sizes $\leq-0.20$ for positively worded concepts (i.e., higher scores indicate better HRQOL), or $\geq 0.20$ for negatively worded concepts (i.e., when higher scores indicate worse HRQOL). For participants that reported no change we predicted they would have negligible SRMs (i.e., $\geq|0.19|$ ). For the group with improvements in either self-reported health or clinician rated function, we predicted that RS/SRMs would be either small (i.e., 0.20 to 0.49 ; we expected 
positive RS/SRMs for positively worded concepts and negative RS/SRMs for negatively worded concepts) or negligible (RS/SRMs $\geq|0.19|$ ); this hypothesis is based on previous literature that suggests globally reported improvements in HRQOL are smaller in magnitude that global ratings of declines. ${ }^{41}$

General linear models (GLMs) were used to examine change over time (from baseline to 12-months and baseline to 24-months) for each of the HDQLIFE and Neuro-QoL HRQOL measures relative to the respective self-reported anchor item or clinician-rated change. Each model included group status (i.e., declines in health, no change in health, or improvements) as a predictor of change in HRQOL. Least-square means and standard errors were calculated for each group to determine whether change over time significantly differed from zero.

Responsiveness would be supported by significant declines in HRQOL relative to self-reported declines in health and clinician-rated declines in function.

We provide a summative table of the different analytical approaches examining responsiveness of the physical HRQOL measures. For each HRQOL measure, responsiveness will be supported if $\geq 75 \%$ of results are in accordance with the proposed hypotheses. ${ }^{42}$

\section{Results}

\section{Study Attrition}

At baseline, 152 participants had premanifest HD, 153 were early-stage, and 67 were late-stage HD. Of the 152 premanifest participants, 110 (72.4\%) had a DCL of 0-1, while 42 (17.6\%) had a DCL of 2-3 (prodromal). A total of 338 individuals (90.9\%) completed the 12month assessment, and 293 (78.8\%) completed the 24-month assessment. Of those participants that were missing the 24-month visit $(n=78), 34$ were lost to follow-up, 15 were 
unable to return or ineligible due to worsening symptoms, 12 withdrew consent or were unwilling to return, and 17 were lost due to "other" reasons (e.g., death, multiple reasons for termination, terminated by examiner). When compared to participants who completed all three assessments, the participants who did not complete the 24-month assessment were more likely to have Late$\mathrm{HD}\left(\mathrm{X}^{2}{ }_{2}=23.4 ; \mathrm{p}<.0001\right)$. Additionally, those who dropped out were more likely to be African American than other races (Fisher's Exact $p=.0132$ ) or have a higher number of CAG repeats $(\mathrm{OR}=1.12 ; \mathrm{p}=.0005)$.

\section{Descriptive Data}

Demographic characteristics for study participants are provided in Table 1 . There were significant differences among the HD groups for each of the physical HRQOL measures at baseline, 12-, and 24-months (Supplemental Table B). In all cases, group differences were in the hypothesized direction (i.e., the premanifest group reported better physical HRQOL than the early-group, who in turn also reported better physical HRQOL than the late-HD group).

\section{Reliability and Measurement Error}

One to three day test-retest reliability for the HDQLIFE and Neuro-QoL measures was excellent. All ICC's were > 0.85 (Supplemental Table B). MID and MCDs are presented in Table 2; MIDs generally ranged from 1 to 3 points depending on the measure and group that was being examined (the largest MIDs were seen for the groups with declines), whereas MDC $_{95}$ values ranged from 4 to 11 points. All SEM values were $<10 \%$ indicating that measurement error was within acceptable limits (Table 2).

\section{Responsiveness}

This article is protected by copyright. All rights reserved. 
Table 3 displays 12- and 24-month RS of physical HRQOL measures, relative to selfreported changes in physical health and clinician-rated changes in function. Effect sizes were consistent with the proposed hypotheses: they were greater in magnitude for those who selfreported declines in health relative to those with no changes or self-reported improvements in health and they were greater in magnitude for those with clinician-rated declines in function relative to those with no changes or improvements in clinician ratings of function. For selfreported change, effect sizes were generally negligible for the group reporting no change regardless of time frame (as hypothesized). For those with self-reported improvement, effect sizes were also generally negligible or small (in the hypothesized direction) for both the 12- and 24-month time frames (as hypothesized). For those with self-reported declines in physical health, effect sizes were generally small regardless of time frame (again as hypothesized). A similar pattern of results was seen for self-reported change using SRM (see Supplemental Table C).

For clinician-rated change, there were generally negligible effect sizes for the group with no change and the group with improvement for the baseline to 12-month time frame (as hypothesized), and there were generally small effect sizes for the group with clinician-rated declines (as hypothesized). From baseline to 24-months, there were typically negligible to small effect sizes for the groups with no change or improvement, and small effect sizes for those with declines. Again, a similar pattern of results was seen for the clinician-rated change using SRM (see Supplemental Table C).

Findings for the GLMs are included in Table 4. Twelve- and 24-month responsiveness was supported for all HRQOL measures relative to self-reported declines in health. In addition, 
while 24-month responsiveness for all of the physical HRQOL measures was supported relative to clinician-rated declines in function, 12-month responsiveness was generally not supported relative to clinician-rated declines (notable exceptions included supported for 12-month responsiveness for Swallowing Difficulties [SF only], Upper Extremities [CAT and SF], and Lower Extremities [CAT and SF]). As hypothesized, participants with no change or improvements in physical health (based on both self-reported and clinician-ratings), did not have significant 12-month changes on the HRQOL measures. Furthermore, the group with improvements (based on both self-reported and clinician-ratings) also generally did not have significant 24-month change on the HRQOL measures (as hypothesized). Finally, with regard to 24-month responsiveness, and not as expected, the no change group (based on both selfreported and clinician-ratings) generally had changes in HRQOL score, albeit these changes were small.

\section{Discussion}

This investigation provides evidence that the HDQLIFE and Neuro-QoL Physical Function measures demonstrate responsiveness to health status changes for persons with HD. The majority of the HDQLIFE and Neuro-QoL physical HRQOL measures met our a priori criterion for responsiveness (see the Supplemental Table D). First, 12- and 24-month effect sizes for patient-reported physical health were larger for individuals with worsening health relative to participants with no change or improvements in physical health; this was true for selfreported decline and clinician-rated decline. Our results are consistent with the responsiveness of the Neuro-QoL measures in other neurological conditions, including Parkinson's disease and adult epilepsy. ${ }^{43-45}$

This article is protected by copyright. All rights reserved. 
In addition, while the group with self-reported and clinician-rated declines exhibited small declines in physical HRQOL at 12-month and 24-month- which is typical for PRO measures there were a few measures that were especially responsive to declines in physical HRQOL. Relative to self-reported declines in health, Swallowing Difficulties and Upper Extremities exhibited moderate effect sizes for both 12- and 24-month change over time. Relative to clinician-rated functional declines, Swallowing Difficulties and Upper Extremity Function were again noteworthy with regard to 24-month change over time.

As expected, there were negligible or small change over time on HRQOL scores for participants with self- and clinician-reported improvements in health. These findings are consistent with previous literature in other populations that find that global improvements in HRQOL - using PROs - tend to be significantly smaller in magnitude than those global ratings of decline. ${ }^{41}$ In addition, and also as expected, 12-month effect sizes were negligible for individuals with no self- or clinical-reported changes in health. Yet, contrary to the expectation of negligible change, there were generally small 24-month effect size declines for the group that did not change based on both self-report and clinician ratings. Thus, participants may experience small declines in HRQOL that either the patients and/or clinicians either are unable to detect and/or that do not affect function.

Some measures did not perform as well as expected. Although 24-month responsiveness for all of the physical HRQOL measures was supported relative to clinicianrated declines in function, support for 12-month responsiveness relative to clinician-rated declines was less robust. We believe that the large variability in TFC-related change (i.e., large standard errors) was likely responsible for the absence of significant 12-month group

This article is protected by copyright. All rights reserved. 
differences. Specifically, individuals with larger TFC-related declines are also more likely to have advanced disease and the reliability of PRO scores are adversely affect by cognitive impairment. ${ }^{46}$

Our responsiveness data were more robust when examining self-reported HRQOL relative to self-reported change and less robust when examining self-reported HRQOL relative to clinician-rated changes. Findings from other populations suggest that clinicians tend to systematically underestimate patient symptoms and functional decline. ${ }^{47-55}$ This is not an issue when both the patient and clinician are providing similar reports for functional abilities and symptoms, but in cases where clinicians and patients are discordant, the path forward may be less clear. It may be that this discrepancy is simply a disagreement between the patient and the clinician about the relative importance of an aspect of function, but HD patients are also less able to communicate their problems as the disease progresses. Importantly, PROs and clinician-ratings provide different information; the overall concordance (or lack thereof) between these reports may provide clinically meaningful information. Given this, and the fact that PROs are not typically included in HD clinical care, clinicians may miss important patient-centered information by relying primarily on clinician ratings of disease progression. Including PROs can help clinicians better care for patients by providing a more complete picture. MIDs and MCDs provided in Table 2 can be used to help guide clinical interpretation of change scores on these PROs.

Our study has some limitations. With regard to the study procedures, a small portion of the sample completed follow-up assessments via telephone, and thus clinician-ratings for several measures were missing for these participants. While there is data to support the 
equivalence of the different administration formats, ${ }^{56-58}$ it is also important to acknowledge that the administration format for the HDQLIFE measures was not consistent across study visits (as detailed above). Also, participants with more advanced disease were more likely to be lost to follow-up, and differential attrition may have made it more difficult to identify significant declines in physical HRQOL. This is not an uncommon problem in HD, and most studies (including clinical trials) target individuals that are either premanifest or early in the disease process. ${ }^{59-61}$ Potential strategies to help mitigate loss to follow-up can include engaging advocacy groups, participation in HD community events, and engagement of social media. ${ }^{62,63}$ Given that individuals with more severe disease were more likely to discontinue participation due to worsening symptoms (and in many cases the inability to provide informed consent at a latter study visit), and that these individuals are precisely the individuals that are experiencing the largest declines in health, we would expect this to negatively impact our findings such that effect sizes are smaller than would be expected for the HD population. This would be consistent with findings in this sample that suggest that reliability of these PROs can be compromised in those in the later stages of the disease process. ${ }^{64}$ Our results are based on a well-educated, primarily non-Hispanic white population, limiting possible generalizability to other racial/ethnic groups. In addition, self-reported changes were also closely matched to each physical HRQOL domain, whereas clinician-rated changes reflected functional changes - which are less closely tied to HRQOL constructs - precluding our ability to directly compare the clinical utility of these measures across these two different types of anchors. In addition, we did not collect data about therapeutic treatments for study participants, and thus the impact of current therapeutic treatments is currently unknown. Furthermore, given that the baseline data informed the 
development of the HDQLIFE CAT and SF administrations, the baseline and 12-month study visits included significantly more items than the 24-month study visit (when most participants were able to complete the shorter administration formats of these measures).

Finally, changes over time were modest, as demonstrated by the small MIDs (Table 2). As often happens, MIDs were generally smaller than the associated $\mathrm{DC}_{95}$ for each measure. Use of $\mathrm{DC}_{95}$ to classify people as changed is a useful conservative approach when one wishes to be $95 \%$ confident that change has occurred. However, if the goal is to optimize accurate classification, then a value closer to the MID is likely to be more accurate.

Taken together, findings support the responsiveness of the HDQLIFE and Neuro-QoL physical HRQOL measures to change over time. We observed small to moderate effect sizes in the absence of an intervention designed to improve HRQOL, so these analyses likely provide a conservative estimate of psychometric performance. As such, data would support using these new measures of HRQOL in both observational and experiemental research study designs in persons with HD, in conjunction with the more commonly administered clinician-rated measures of physical functioning. Findings also highlight the importance of complementing clinician-ratings with patient-report of HRQOL to better understand the impact that an intervention has on an individual affected with HD. In this manner, a more patient-centered approach to HD treatment should include an assessment of health-related quality of life. As such, HRQOL physical function measures have the potential to provide clinically relevant information that should be considered in the context of the standard clinical exam (which does not typically include PROs) in persons with HD.

This article is protected by copyright. All rights reserved. 
Acknowledgements: Work on this manuscript was supported by the National Institutes of Health (NIH), National Institute of Neurological Disorders and Stroke (R01NS077946) and the National Center for Advancing Translational Sciences (UL1TR000433). In addition, a portion of this study sample was collected in conjunction with the Predict-HD study. The PredictHD study was supported by the $\mathrm{NIH}$, National Institute of Neurological Disorders and Stroke (R01NS040068), the NIH, Center for Inherited Disease Research (provided supported for sample phenotyping), and the CHDI Foundation (award to the University of lowa). We thank the University of lowa, the Investigators and Coordinators of this study, the study participants, the National Research Roster for Huntington Disease Patients and Families, the Huntington Study Group, and the Huntington's Disease Society of America. We acknowledge the assistance of Jeffrey D. Long, Hans J. Johnson, Jeremy H. Bockholt, Roland Zschiegner, and Jane S. Paulsen. We also acknowledge Roger Albin, Kelvin Chou, and Henry Paulsen for the assistance with participant recruitment. The content is solely the responsibility of the authors and does not necessarily represent the official views of the $\mathrm{NIH}$.

HDQLIFE Site Investigators and Coordinators: Noelle Carlozzi, Praveen Dayalu, Stephen Schilling, Amy Austin, Matthew Canter, Siera Goodnight, Jennifer Miner, Nicholas Migliore (University of Michigan, Ann Arbor, MI); Jane Paulsen, Nancy Downing, Isabella DeSoriano, Courtney Shadrick, Amanda Miller (University of lowa, Iowa City, IA); Kimberly Quaid, Melissa Wesson (Indiana University, Indianapolis, IN); Christopher Ross, Gregory Churchill, Mary Jane Ong (Johns Hopkins University, Baltimore, MD); Susan Perlman, Brian Clemente, Aaron Fisher, Gloria Obialisi, Michael Rosco (University of California Los Angeles, Los Angeles, CA); Michael McCormack, Humberto Marin, Allison Dicke (Rutgers University, Piscataway, NJ); Joel Perlmutter, Stacey Barton, Shineeka Smith (Washington University, St. Louis, MO); Martha Nance, Pat Ede (Struthers Parkinson's Center); Stephen Rao, Anwar Ahmed, Michael Lengen, Lyla Mourany, Christine Reece, (Cleveland Clinic Foundation, Cleveland, OH); Michael Geschwind, Joseph Winer (University of California - San Francisco, San Francisco, CA), David Cella, Richard Gershon, Elizabeth Hahn, Jin-Shei Lai (Northwestern University, Chicago, IL). 


\section{Author Roles:}

Carlozzi, N.E.: $\quad$ Study Principal Investigator; Data Collection Site; Oversight for Statistical Analysis; Initial draft of Method, Results and Discussion; Incorporation of revisions

Boileau, N. R. $\quad$ Study Research Coordinator; Primary Data Analyst Responsible for Majority of Statistical Analyses; Assistance with Methods and Results Sections; Review and Feedback on manuscript drafts

Chou, K.L.

Study Collaborator; Review and Feedback on manuscript drafts (specific contributions with regard to framing the introduction and discussion in the context of the current HD literature)

Ready, R.E. $\quad$ Study Consultant; Assistance with presenting the results in a manner that is readily understandable for the journal audience; Review and Feedback on manuscript drafts

Cella, D.

Study Co-Investigator; Neuro-QoL Investigative Team Principal Investigator; Review and Feedback on manuscript drafts (specific contributions to presenting the psychometric findings)

McCormack, M. Study Co-Investigator; Review and Feedback on manuscript drafts (specific contributions to the Introduction)

Miner, J.A.

Study Project Manager; Assistance with Methods Section; Review and Feedback on manuscript drafts

Dayalu, P.

Study Co-Investigator; Initial Draft of Abstract; Assistance Writing Discussion Including Integration of Findings with Existing HD Literature; Review and Feedback on manuscript drafts 


\section{FUNDING STATEMENTS \& CONFLICTS OF INTEREST:}

Carlozzi, N.E. is supported by research grants from the NIH, the Neilsen Foundation, and CHDI, as well as contracts from Goldfinch, LLC, and Health and Human Services - Centers for Medicare \& Medicaid Services; she receives honoraria for her role on the CHDI scientific advisory board; she declares no conflicts of interest.

Boileau, N.R. has been supported by research grants from the $\mathrm{NIH}$, the Neilsen Foundation, and CHDI.

Chou KL has received research support from the NIH (NS091856-01, NS10061102, NS107158), Parkinson Study Group (STEADY-PD III, SURE-PD3, NILO-PD), and Eli Lilly. He has been a consultant for Accordant, Boston Scientific, and Sunovion Pharmaceuticals. He also receives royalties from UpToDate and Springer Publishing.

Ready, R.E. declares that she has no conflicts of interest.

Cella, D. receives grant funding from the National Institutes of Health and reports that he has no conflicts of interest.

McCormack, M.K. currently has grants from the NJ Department of Health; he declares no conflicts of interest.

Miner, J.A. is supported by funding from the NIH, PCORI, the Craig $\mathrm{H}$. Neilsen Foundation, and Goldfinch Bio; she declares no conflicts of interest.

Dayalu, P. is supported by grants from Vaccinex and CHDI. He declares no conflicts of interest. 


\section{References}

1. Duff K, Paulsen J, Mills J, et al. Mild cognitive impairment in prediagnosed Huntington disease. Neurology. 2010;75(6):500-507.

2. Snowden J, Craufurd D, Griffiths H, Thompson J, Neary D. Longitudinal evaluation of cognitive disorder in Huntington's disease. J Int Neuropsychol Soc. 2001;7(1):33-44.

3. Paulsen JS, Ready RE, Hamilton JM, Mega MS, Cummings JL. Neuropsychiatric aspects of Huntington's disease. J Neurol Neurosurg Psychiatry. 2001;71(3):310-314.

4. Duff K, Paulsen JS, Beglinger LJ, Langbehn DR, Stout JC, Predict HDlotHSG. Psychiatric symptoms in Huntington's disease before diagnosis: the predict-HD study. Biol Psychiatry. 2007;62(12):1341-1346.

5. Long JD, Paulsen JS, Marder K, et al. Tracking motor impairments in the progression of Huntington's disease. Mov Disord. 2014;29(3):311-319.

6. Maroof DA, Gross AL, Brandt J. Modeling longitudinal change in motor and cognitive processing speed in presymptomatic Huntington's disease. J Clin Exp Neuropsychology. 2011;33(8):901-909.

7. Marder $\mathrm{K}$, Zhao $\mathrm{H}$, Myers $\mathrm{RH}$, et al. Rate of functional decline in Huntington's disease. Neurology. 2000;54(2):452.

8. Paulsen JS, Wang C, Duff $\mathrm{K}$, et al. Challenges assessing clinical endpoints in early Huntington disease. Mov Disord. 2010;25(15):2595-2603.

9. Basch E. The Missing Voice of Patients in Drug-Safety Reporting. N Engl J Med. 2010;362(10):865-869.

This article is protected by copyright. All rights reserved. 
10. Busse M, Quinn L, Dawes $\mathrm{H}$, et al. Supporting physical activity engagement in people with Huntington's disease (ENGAGE-HD): study protocol for a randomized controlled feasibility trial. Trials. 2014;15:487.

11. Busse M, Quinn L, Debono K, et al. A randomized feasibility study of a 12-week community-based exercise program for people with Huntington's disease. Journal of neurologic physical therapy : JNPT. 2013;37(4):149-158.

12. Dawes $\mathrm{H}$, Collett J, Debono $\mathrm{K}$, et al. Exercise testing and training in people with Huntington's disease. Clin Rehabil. 2015;29(2):196-206.

13. Khalil H, Quinn L, van Deursen R, et al. What effect does a structured home-based exercise programme have on people with Huntington's disease? A randomized, controlled pilot study. Clinical rehabilitation. 2013;27(7):646-658.

14. Quinn L, Busse M, Khalil H, Richardson S, Rosser A, Morris H. Client and therapist views on exercise programmes for early-mid stage Parkinson's disease and Huntington's disease. Disabil Rehabil. 2010;32(11):917-928.

15. Quinn L, Hamana K, Kelson M, et al. A randomized, controlled trial of a multi-modal exercise intervention in Huntington's disease. Parkinsonism Relat Disord. 2016;31:4652.

16. Carlozzi NE, Downing NR, Schilling SG, et al. The development of a new computer adaptive test to evaluate chorea in Huntington disease: HDQLIFE Chorea. Qual Life Res. 2016.

This article is protected by copyright. All rights reserved. 
17. Carlozzi NE, Schilling SG, Lai JS, et al. HDQLIFE: Development and assessment of health-related quality of life in Huntington disease (HD). Qual Life Res. 2016;25(10):2441-2455.

18. Carlozzi NE, Schilling SG, Lai JS, et al. HDQLIFE: the development of two new computer adaptive tests for use in Huntington disease, Speech Difficulties, and Swallowing Difficulties. Qual Life Res. 2016.

19. Cella D, Nowinski C, Peterman A, et al. The Neurology Quality of Life Measurement (Neuro-QOL) Initiative. Arch Phys Med Rehabil. 2011;92(Suppl 1):S28-S36.

20. Gershon RC, Lai JS, Bode R, et al. Neuro-QOL: quality of life item banks for adults with neurological disorders: item development and calibrations based upon clinical and general population testing. Qual Life Res. 2011.

21. Carlozzi NE, Ready R, Frank S, et al. Patient-Reported Outcomes in Huntington Disease: Neuro-QOL and HDQLIFE Physical Function Measures. Mov Disord. 2017;32(7):1096-1102.

22. Pickard AS, Johnson JA, Feeny DH. Responsiveness of generic health-related quality of life measures in stroke. Qual Life Res. 2005;14(1):207-219.

23. Jackson W, TA N. Effective serial measurement of cognitive orientation in rehabilitation: the Orientation Log. Arch Phys Med Rehabil. 1998;79(6):718-720.

24. Unified Huntington's Disease Rating Scale: reliability and consistency. Huntington Study Group. Mov Disord. 1996;11(2):136-142.

25. Shoulson I. Huntington disease: functional capacities in patients treated with neuroleptic and antidepressant drugs. Neurology. 1981;31:1333-1335.

This article is protected by copyright. All rights reserved. 
26. Carlozzi NE, Downing NR, Schilling SG, et al. The development of a new computer adaptive test to evaluate chorea in Huntington disease: HDQLIFE Chorea. Qual Life Res. 2016;25(10):2429-2439.

27. Carlozzi NE, Schilling SG, Lai JS, et al. HDQLIFE: the development of two new computer adaptive tests for use in Huntington disease, Speech Difficulties, and Swallowing Difficulties. Qual Life Res. 2016;25(10):2417-2427.

28. Choi SW, Podrabsky T, McKinney N. Firestar-D: Computerized Adaptive Testing Simulation Program for Dichotomous Item Response Theory Models. Appl Psych Meas. 2012;36(1):67-68.

29. Chang KW, Austin A, Yeaman J, et al. Health-Related Quality of Life Components in Children With Neonatal Brachial Plexus Palsy: A Qualitative Study. PM \& $R$ : the journal of injury, function, and rehabilitation. 2017;9(4):383-391.

30. SAS 9.4 language reference concepts [computer program]. Cary, NC: SAS Institute; 2013.

31. Bulmer MG. Principles of statistics. New York: Dover Publications; 1979.

32. Cohen J. Statistical power analysis for the behavioral sciences. New York: Academic Press; 1969.

33. Jaescke R, Singer J, Guyatt GH. Measurement of Health Status: Ascertaining the Minimal Clinically Important Difference. Control Clin Trials. 1989;10:407-415.

34. King MT. A point of minimal important difference (MID): a critique of terminology and methods. Expert Rev Pharmacoeconomics Outcomes Res. 2011;11(2):171-184.

This article is protected by copyright. All rights reserved. 
35. Beaton DE, Bombardier C, Katz JN, et al. Looking for important change/differences in studies of responsiveness. OMERACT MCID Working Group. Outcome Measures in Rheumatology. Minimal Clinically Important Difference. J Rheumatol. 2001;28(2):400405.

36. Wyrwich KW, Tierney WM, Wolinsky FD. Further evidence supporting an SEM-based criterion for identifying meaningful intra-individual changes in health-related quality of life. J Clin Epidemiol. 1999;52(9):861-873.

37. Flansbjer U, Holmback AM, Downham D, Patten C, Lexell J. Reliability of Gait Performance Tests in Men and Women with Hemiparesis After Stroke. J Rehabil Med. $2005 ; 37: 75-82$.

38. Guyatt G, Walter S, Norman G. Measuring change over time: assessing the usefulness of evaluative instruments. J Chronic Dis. 1987;40(2):171-178.

39. Cohen J. A power primer. Psychol Bull. 1992;112(1):155-159.

40. Kopjar B. The SF-36 health survey: a valid measure of changes in health status after injury. Inj Prev. 1996;2:135-139.

41. Dineen K, Cella D, Hahn EA, Yount S. Meaningful change in cancer-specific quality-oflife scores: Differences between improvement and worsening. Clinical Therapeutics. $2002 ; 24: 41-42$.

42. Terwee CB, Bot SD, de Boer MR, et al. Quality criteria were proposed for measurement properties of health status questionnaires. J Clin Epidemiol. 2007;60(1):34-42.

This article is protected by copyright. All rights reserved. 
43. Nowinski CJ, Siderowf A, Simuni T, Wortman C, Moy C, Cella D. Neuro-QoL healthrelated quality of life measurement system: Validation in Parkinson's disease. Movement Disord. 2016;31(5):725-733.

44. Salsman JM, Victorson D, Choi SW, et al. Development and validation of the positive affect and well-being scale for the neurology quality of life (Neuro-QOL) measurement system. Qual Life Res. 2013;22(9):2569-2580.

45. Victorson D, Cavazos JE, Holmes GL, et al. Validity of the Neurology Quality-of-Life (Neuro-QoL) measurement system in adult epilepsy. Epilepsy \& behavior : E\&B. $2014 ; 31: 77-84$.

46. Carlozzi NE, Paulsen JS, Stout J, et al. Understanding Patient-Reported Outcome Measures in Huntington Disease: At What Point is Cognitive Impairment Related to Poor Measurement Reliability? Neurotherapeutics. 2017;14(1):239-240.

47. Rodriguez LV, Blander DS, Dorey F, Raz S, Zimmern P. Discrepancy in patient and physician perception of patient's quality of life related to urinary symptoms. Urology. 2003;62(1):49-53.

48. Justice $\mathrm{AC}$, Chang $\mathrm{CH}$, Rabeneck L, Zackin R. Clinical importance of provider-reported HIV symptoms compared with patient-report. Med Care. 2001;39(4):397-408.

49. Kalarchian MA, Wilson GT, Brolin RE, Bradley L. Assessment of eating disorders in bariatric surgery candidates: Self-report questionnaire versus interview. Int J Eat Disorder. 2000;28(4):465-469.

50. Lindstrom E, Lewander T, Malm U, Malt UF, Lublin H, Ahlfors UG. Patient-rated versus clinician-rated side effects of drug treatment in schizophrenia - Clinical validation of a

This article is protected by copyright. All rights reserved. 
self-rating version of the UKU Side Effect Rating Scale (UKU-SERS-Pat). Nord J Psychiat. 2001;55:5-+.

51. Luoma ML, Hakamies-Blomqvist L, Sjostrom J, et al. Physical performance, toxicity, and quality of life as assessed by the physician and the patient. Acta oncologica. 2002;41(1):44-49.

52. Neville C, Clarke AE, Joseph L, Belisle P, Ferland D, Fortin PR. Learning from discordance in patient and physician global assessments of systemic lupus erythematosus disease activity. Journal of Rheumatology. 2000;27(3):675-679.

53. Neville C, Joseph L, Clarke AE, Belisle P, Ferland D, Fortin PR. Learning from discordance in patient and physician global assessments of lupus disease activity. Arthritis Rheum. 1997;40(9):845-845.

54. Sneeuw KCA, Aaronson NK, Sprangers MAG, Detmar SB, Wever LDV, Schornagel JH. Comparison of patient and proxy EORTC QLQ-C30 ratings in assessing the quality of life of cancer patients. J Clin Epidemiol. 1998;51(7):617-631.

55. Sneeuw KCA, Aaronson NK, Sprangers MAG, Detmar SB, Wever LDV, Schornagel JH. Evaluating the quality of life of cancer patients: assessments by patients, significant others, physicians and nurses. Brit J Cancer. 1999;81(1):87-94.

56. Bjorner JB, Chang CH, Thissen D, Reeve BB. Developing tailored instruments: item banking and computerized adaptive assessment. Qual Life Res. 2007;16 Suppl 1:95108.

57. Rose M, Bjorner JB, Becker J, Fries JF, Ware JE. Evaluation of a preliminary physical function item bank supported the expected advantages of the Patient-Reported

This article is protected by copyright. All rights reserved. 
Outcomes Measurement Information System (PROMIS). J Clin Epidemiol. 2008;61(1):17-33.

58. Rose M, Bjorner JB, Gandek B, Bruce B, Fries JF, Ware JE, Jr. The PROMIS Physical Function item bank was calibrated to a standardized metric and shown to improve measurement efficiency. J Clin Epidemiol. 2014;67(5):516-526.

59. Frost C, Mulick A, Scahill RI, et al. Design optimization for clinical trials in early-stage manifest Huntington's disease. Mov Disord. 2017;32(11):1610-1619.

60. Paulsen JS, Lourens S, Kieburtz K, Zhang Y. Sample enrichment for clinical trials to show delay of onset in huntington disease. Mov Disord. 2019;34(2):274-280.

61. Paulsen JS, Long JD, Johnson HJ, et al. Clinical and Biomarker Changes in Premanifest Huntington Disease Show Trial Feasibility: A Decade of the PREDICT-HD Study. Front Aging Neurosci. 2014;6:78.

62. Goodman L, Sia C, Carnes R, et al. Advocacy Recruiting for Huntington's Disease Clinical Trials. PLoS Curr. 2011;3:RRN1230.

63. Kinel S, McCarthy L, Kayson E, et al. Project AWARE: Assessing awareness, willingness, and ability of the Huntington disease community to participate in Huntington disease clinical trials. Paper presented at: Huntington Study Group2011; INdianapolis, IN.

64. Carlozzi NE, Schilling S, Kratz AL, Paulsen JS, Frank S, Stout JC. Understanding patient-reported outcome measures in Huntington disease: at what point is cognitive impairment related to poor measurement reliability? Qual Life Res. 2018.

This article is protected by copyright. All rights reserved. 
Table 1

Baseline descriptive data

\begin{tabular}{|c|c|c|c|c|}
\hline Variable & $\begin{array}{c}\text { Premanifest- } \\
\text { HD } \\
(\mathrm{N}=152) \\
\end{array}$ & $\begin{array}{c}\text { Early-HD } \\
(\mathrm{N}=153)\end{array}$ & $\begin{array}{l}\text { Late-HD } \\
(\mathrm{N}=67)\end{array}$ & $\begin{array}{c}\text { Combined } \\
\text { Sample } \\
(\mathrm{N}=372) \\
\end{array}$ \\
\hline \multicolumn{5}{|l|}{ Age (Years)* } \\
\hline M (SD) & $43.0(12.4)$ & $53.0(11.9)$ & $55.0(10.7)$ & $49.3(13.0)$ \\
\hline \multicolumn{4}{|l|}{ Gender (\%) } & 58.6 \\
\hline Male & 35.5 & 46.4 & 43.3 & 41.4 \\
\hline \multicolumn{5}{|l|}{ Race (\%)* } \\
\hline White & 98.0 & 95.4 & 92.5 & 95.8 \\
\hline African American & 0.0 & 1.3 & 7.5 & 1.9 \\
\hline Other & 1.3 & 3.3 & 0.0 & 1.9 \\
\hline Unknown & 0.7 & 0.0 & 0.0 & 0.3 \\
\hline \multicolumn{5}{|l|}{ Ethnicity (\%) } \\
\hline Not Hispanic or Latino & 92.1 & 91.5 & 97.0 & 92.7 \\
\hline Hispanic or Latino & 1.3 & 5.2 & 0.0 & 2.7 \\
\hline \\
\hline $\begin{array}{l}\text { Education (\# of years)* } \\
M(S D) \\
\text { Marital Status (\%) }\end{array}$ & $16.1(2.8)$ & $14.8(2.8)$ & $14.1(2.5)$ & $15.2(2.8)$ \\
\hline Single, Never Married & 15.1 & 15.2 & 9.0 & 14.1 \\
\hline Married & 69.1 & 57.6 & 65.7 & 63.8 \\
\hline Separated/Divorced & 13.2 & 19.9 & 22.4 & 17.6 \\
\hline Widowed & 0.0 & 3.3 & 3.0 & 1.9 \\
\hline \multicolumn{5}{|l|}{ Living with Partner } \\
\hline $\begin{array}{l}\text { \# Converted (Baseline } \\
\text { to 12-months) }\end{array}$ & 8 & 12 & -- & 19 \\
\hline \# Converted (Baseline & 16 & 43 & -- & 57 \\
\hline \multicolumn{4}{|l|}{ CAG Repeats } & $42.5(3.7)$ \\
\hline \multicolumn{5}{|c|}{ Note. $\mathrm{HD}=$ Huntington disease. ${ }^{*}$ indicates significant group differences: premanifest } \\
\hline \multicolumn{5}{|c|}{ participants were on average 10 years younger than the Early-HD group and 12 years } \\
\hline \multicolumn{5}{|c|}{ younger than the late-HD group $(F[2,344]=37.63 ; p<.0001)$; the premanifest group had } \\
\hline \multicolumn{5}{|c|}{ approximately one more year of attainment in education $(F[2,337]=13.4 ; p<.0001)$; the } \\
\hline Late-HD group had a sig & antly higher & ortion of & Amorino & $\mathrm{n}$ the otl \\
\hline
\end{tabular}

This article is protected by copyright. All rights reserved. 
two groups (Fisher's Exact $\mathrm{p}=$.0048). \# Converted indicates the number of participants who moved to next stage from baseline to follow-up. Baseline to 24-month conversion also includes those who converted from 12- to 24-month.

This article is protected by copyright. All rights reserved. 


\section{Table 2}

\section{2-month Minimal Important Differences, Minimum Detectable Change, and Standard Error of Measurement}

\begin{tabular}{|c|c|c|c|c|c|}
\hline & & IID & & & \\
\hline & $\begin{array}{l}\text { Decline in } \\
\text { self-reported } \\
\text { health } \\
M(\text { SD) }\end{array}$ & $\begin{array}{l}\text { Improvement in } \\
\text { self-reported } \\
\text { health } \\
\text { M(SD) }\end{array}$ & DC\% ${ }_{95}$ (LDC, UDC) & SEM & SEM \% \\
\hline Chorea CAT & $1.03(4.33)$ & $-0.47(5.63)$ & $7.80(-7.40,8.20)$ & 2.81 & 5.71 \\
\hline Chorea SF & $0.89(4.90)$ & $0.18(6.42)$ & $7.54(-7.04,8.04)$ & 2.72 & 5.49 \\
\hline Speech Difficulties CAT & $1.36(6.53)$ & $-1.43(7.99)$ & $5.91(-5.61,6.21)$ & 2.13 & 4.41 \\
\hline Speech Difficulties SF ${ }^{\text {b }}$ & $1.15(6.19)$ & $-3.36(7.78)$ & $7.28(-7.18,7.38)$ & 2.62 & 5.42 \\
\hline Swallowing Difficulties CAT ${ }^{a}$ & $2.62(4.46)$ & $-1.00(6.68)$ & $4.13(-3.63,4.63)$ & 1.49 & 2.99 \\
\hline Swallowing Difficulties SF ${ }^{a}$ & $2.76(4.52)$ & 1.08 (10.03) & $5.77(-4.77,6.77)$ & 2.08 & 4.18 \\
\hline Upper Extremities CAT^^ & $-2.56(5.96)$ & $-0.41(6.45)$ & $5.65(-6.75,4.55)$ & 2.04 & 4.59 \\
\hline Upper Extremities SF^a & $-2.87(6.89)$ & $-1.17(4.85)$ & $10.58(-12.08,9.08)$ & 3.82 & 8.62 \\
\hline Lower Extremities CAT^^ & $-2.12(5.60)$ & $-0.46(5.92)$ & $7.55(-8.25,6.85)$ & 2.73 & 5.62 \\
\hline Lower Extremities SF^ & $-2.31(5.72)$ & $-0.25(7.16)$ & $6.31(-7.61,5.01)$ & 2.28 & 4.65 \\
\hline
\end{tabular}

Note: CAT=Computer Adaptive Test; SF=Short Form; MID=Minimal Important Difference; SEM=Standard Error of Measurement; $D C_{95}=$ Detectable Change (95\% Confidence); ${ }^{\wedge}=$ higher scores indicate better HRQOL. LDC $=$ Lower 
Detectable Change (95\% Confidence); UDC = Upper Detectable Change (95\% Confidence); LDC and UDC calculated in reference to 12-month change in HRQOL

${ }^{a}$ Health decline group differs from no change group

${ }^{\mathrm{b}}$ Health decline group differs from improvement group

\section{Table 3}

\section{Guyatt's Responsiveness Statistics for changes in HRQOL}

\begin{tabular}{|c|c|c|c|c|c|c|c|c|c|c|c|c|}
\hline & \multicolumn{12}{|c|}{ Self-Reported Changes in Physical Health (from anchor items) } \\
\hline & \multicolumn{6}{|c|}{ Baseline to 12-months } & \multicolumn{6}{|c|}{ Baseline to 24-months } \\
\hline & \multicolumn{2}{|c|}{ No Change in Health } & \multicolumn{2}{|c|}{ Declines in Health } & \multicolumn{2}{|c|}{ Improvement in Health } & \multicolumn{2}{|c|}{ No Change in Health } & \multicolumn{2}{|c|}{ Declines in Health } & \multicolumn{2}{|c|}{$\frac{\text { Improvement }}{\text { in Health }}$} \\
\hline & $\underline{N}$ & SRM & $\underline{N}$ & $\underline{\text { SRM }}$ & $\underline{N}$ & SRM & $\underline{N}$ & SRM & $\underline{N}$ & $\underline{\text { SRM }}$ & $\underline{N}$ & $\underline{\text { SRM }}$ \\
\hline Chorea CAT & 223 & $\overline{0.10}$ & $\overline{74}$ & $\overline{0.26}$ & 24 & -0.30 & 139 & $\overline{0.20}$ & $\overline{78}$ & $\overline{0.30}$ & 22 & 0.15 \\
\hline Chorea SF & 220 & 0.06 & 73 & 0.20 & 24 & -0.19 & 137 & 0.21 & 77 & 0.44 & 22 & 0.27 \\
\hline Speech Difficulties CAT & 225 & 0.05 & 76 & 0.21 & 21 & -0.24 & 142 & 0.14 & 83 & 0.28 & 18 & -0.02 \\
\hline Speech Difficulties SF & 224 & 0.00 & 75 & 0.18 & 21 & -0.35 & 144 & 0.12 & 81 & 0.26 & 18 & -0.15 \\
\hline Swallowing Difficulties CAT & 239 & 0.03 & 64 & 0.58 & 21 & -0.22 & 145 & 0.09 & 78 & 0.61 & 20 & 0.10 \\
\hline Swallowing Difficulties SF & 241 & 0.08 & 61 & 0.64 & 21 & 0.01 & 145 & 0.19 & 76 & 0.71 & 20 & 0.40 \\
\hline Upper Extremities CAT^ & 210 & -0.11 & 80 & -0.46 & 33 & 0.15 & 127 & -0.36 & 90 & -0.47 & 28 & -0.12 \\
\hline Upper Extremities SF^ & 211 & -0.12 & 80 & -0.44 & 33 & -0.02 & 128 & -0.17 & 90 & -0.43 & 28 & -0.06 \\
\hline Lower Extremities CAT^ $^{\wedge}$ & 197 & -0.14 & 63 & -0.34 & 63 & 0.05 & 125 & -0.29 & 66 & -0.58 & 56 & -0.06 \\
\hline \multirow[t]{3}{*}{ Lower Extremities SF^^} & 197 & -0.13 & 63 & -0.40 & 63 & -0.06 & 125 & -0.26 & 66 & -0.46 & 56 & 0.08 \\
\hline & \multicolumn{12}{|c|}{ Clinician-Rated Changes in Function (from TFC) } \\
\hline & \multicolumn{6}{|c|}{ Baseline to 12-months } & \multicolumn{6}{|c|}{ Baseline to 24-months } \\
\hline
\end{tabular}

This article is protected by copyright. All rights reserved. 


\begin{tabular}{|c|c|c|c|c|c|c|c|c|c|c|c|c|}
\hline & \multicolumn{2}{|c|}{ No Change in Health } & \multicolumn{2}{|c|}{ Declines in Health } & \multicolumn{2}{|c|}{$\underline{\text { Improvement in Health }}$} & \multicolumn{2}{|c|}{ No Change in Health } & \multicolumn{2}{|c|}{ Declines in Health } & \multicolumn{2}{|c|}{$\frac{\text { Improvement }}{\underline{\text { in Health }}}$} \\
\hline & $\underline{\mathrm{N}}$ & $\underline{\mathrm{SRM}}$ & $\underline{\mathrm{N}}$ & $\underline{\mathrm{SRM}}$ & $\underline{\mathrm{N}}$ & $\underline{\mathrm{SRM}}$ & $\underline{\mathrm{N}}$ & $\underline{\text { SRM }}$ & $\underline{N}$ & $\underline{\text { SRM }}$ & $\underline{N}$ & $\underline{\mathrm{SRM}}$ \\
\hline Chorea CAT & 238 & 0.06 & 68 & 0.22 & 23 & 0.20 & 216 & 0.24 & 45 & 0.31 & 28 & -0.28 \\
\hline Chorea SF & 234 & 0.04 & 68 & 0.10 & 23 & 0.07 & 214 & 0.30 & 44 & 0.46 & 27 & 0.00 \\
\hline Speech Difficulties CAT & 236 & 0.01 & 68 & 0.17 & 23 & -0.06 & 216 & 0.16 & 44 & 0.32 & 28 & 0.01 \\
\hline Speech Difficulties SF & 235 & -0.03 & 68 & 0.14 & 23 & -0.09 & 216 & 0.12 & 45 & 0.37 & 27 & -0.11 \\
\hline Swallowing Difficulties CAT & 236 & 0.12 & 68 & 0.11 & 23 & -0.25 & 216 & 0.17 & 44 & 0.53 & 28 & 0.33 \\
\hline Swallowing Difficulties SF & 236 & 0.15 & 69 & 0.30 & 22 & -0.15 & 215 & 0.33 & 45 & 0.54 & 26 & 0.42 \\
\hline Upper Extremities CAT^^ & 233 & -0.05 & 66 & -0.51 & 23 & -0.04 & 215 & -0.27 & 41 & -0.75 & 26 & -0.49 \\
\hline Upper Extremities SF^^ & 235 & -0.15 & 66 & -0.41 & 23 & 0.24 & 217 & -0.25 & 42 & -0.42 & 26 & 0.11 \\
\hline Lower Extremities CAT^ & 233 & -0.07 & 66 & -0.39 & 23 & 0.07 & 215 & -0.24 & 41 & -0.53 & 26 & -0.21 \\
\hline Lower Extremities SF^^ & 234 & -0.10 & 66 & -0.44 & 23 & -0.01 & 217 & -0.28 & 42 & -0.48 & 26 & -0.07 \\
\hline
\end{tabular}

This article is protected by copyright. All rights reserved. 


\section{Table 4}

\section{Responsiveness relative to self-reported changes in health and clinician-rated changes in function}

\begin{tabular}{|c|c|c|c|c|c|c|}
\hline & \multicolumn{3}{|c|}{ 12-month Responsiveness } & \multicolumn{3}{|c|}{ 24-month Responsiveness } \\
\hline & $\begin{array}{l}\frac{\text { No Change }}{\text { in Function }} \\
\text { Least } \\
\text { squared } \\
\text { mean (SE) }\end{array}$ & $\begin{array}{l}\frac{\text { Declines in }}{\text { Function }} \\
\text { Least } \\
\text { squared } \\
\text { mean (SE) }\end{array}$ & $\begin{array}{l}\frac{\text { Improvement }}{\text { in Function }} \\
\text { Least squared } \\
\text { mean (SE) }\end{array}$ & $\begin{array}{c}\frac{\text { No Change }}{\text { in Function }} \\
\frac{\text { Least }}{\text { squared }} \\
\text { mean (SE) }\end{array}$ & $\begin{array}{l}\frac{\text { Declines in }}{\text { Function }} \\
\text { Least squared } \\
\text { mean (SE) }\end{array}$ & $\begin{array}{l}\frac{\text { Improvement }}{\text { in Function }} \\
\text { Least squared } \\
\text { mean (SE) }\end{array}$ \\
\hline & \multicolumn{6}{|c|}{ Self-Reported Changes in Physical Health (from anchor items) } \\
\hline Chorea CAT & $0.50(0.33)$ & $1.12(0.57)$ & $-1.69(1.01)$ & $1.24(0.51)^{\star}$ & $1.66(0.68)^{\star}$ & $0.95(1.28)$ \\
\hline Chorea SF & $0.29(0.35)$ & $0.95(0.61)$ & $-1.16(1.06)$ & $1.07(0.46)^{\star}$ & $2.53(0.61)^{\star}$ & $1.34(1.14)$ \\
\hline Speech Difficulties CAT & $0.25(0.40)$ & $1.36(0.68)^{*}$ & $-2.05(1.30)$ & $0.94(0.56)$ & $1.78(0.73)^{\star}$ & $-0.20(1.57)$ \\
\hline Speech Difficulties SF & $0.02(0.38)$ & $1.12(0.65)$ & $-2.95(1.23)^{\star}$ & $0.79(0.53)$ & $1.61(0.71)^{\star}$ & $-1.02(1.50)$ \\
\hline Swallowing Difficulties CAT & $0.17(0.39)$ & $2.81(0.76)^{\star}$ & $-1.81(1.32)$ & $0.59(0.54)$ & $3.55(0.74)^{\star}$ & $0.70(1.46)$ \\
\hline Swallowing Difficulties SF & $0.49(0.39)$ & $3.19(0.77)^{\star}$ & $0.14(1.31)$ & $1.14(0.50)^{\star}$ & $4.24(0.69)^{\star}$ & $2.44(1.34)$ \\
\hline Upper Extremities CAT^^ & $-0.65(0.43)$ & $-2.76(0.69)^{*}$ & $1.20(1.08)$ & $-1.82(0.51)^{*}$ & $-3.01(0.61)^{*}$ & $-0.80(1.09)$ \\
\hline Upper Extremities SF^ & $-0.71(0.43)$ & $-3.03(0.70)^{*}$ & $-0.12(1.08)$ & $-1.03(0.57)$ & $-3.05(0.68)^{\star}$ & $-0.39(1.22)$ \\
\hline Lower Extremities $\mathrm{CAT}^{\wedge}$ & $-0.77(0.42)$ & $-1.94(0.74)^{\star}$ & $0.37(0.74)$ & $-1.85(0.58)^{*}$ & $-3.72(0.79)^{\star}$ & $-0.40(0.86)$ \\
\hline \multirow[t]{2}{*}{ Lower Extremities SF^ } & $-0.69(0.41)$ & $-2.24(0.72)^{\star}$ & $-0.41(0.72)$ & $-1.43(0.53)^{\star}$ & $-3.25(0.73)^{\star}$ & $0.45(0.79)$ \\
\hline & \multicolumn{6}{|c|}{ Clinician-Rated Changes in Function (from TFC) } \\
\hline Chorea CAT & $0.32(0.32)$ & $1.13(0.59)$ & $0.66(1.02)$ & $1.34(0.40)^{\star}$ & $2.24(0.87)^{\star}$ & $-1.44(1.11)$ \\
\hline Chorea SF & $0.21(0.34)$ & $0.63(0.63)$ & $0.33(1.08)$ & $1.50(0.37)^{\star}$ & $3.23(0.81)^{*}$ & $-0.01(1.03)$ \\
\hline Speech Difficulties CAT & $0.08(0.39)$ & $1.31(0.72)$ & $-0.38(1.25)$ & $1.04(0.44)^{\star}$ & $2.54(0.98)^{\star}$ & $0.05(1.23)$ \\
\hline Speech Difficulties SF & $-0.14(0.37)$ & $1.03(0.68)$ & $-0.54(1.18)$ & $0.73(0.42)$ & $2.71(0.92)^{\star}$ & $-0.50(1.19)$ \\
\hline Swallowing Difficulties CAT & $0.66(0.40)$ & $0.87(0.75)$ & $-1.36(1.28)$ & $0.97(0.44)^{\star}$ & $4.66(0.97)^{\star}$ & $2.33(1.22)$ \\
\hline Swallowing Difficulties SF & $0.77(0.39)$ & $2.43(0.73)^{\star}$ & $-0.95(1.28)$ & $1.74(0.41)^{\star}$ & $4.58(0.89)^{\star}$ & $2.72(1.17)^{\star}$ \\
\hline Upper Extremities $\mathrm{CAT}^{\wedge}$ & $-0.28(0.40)$ & $-3.71(0.76)^{\star}$ & $-0.19(1.28)$ & $-1.45(0.38)^{\star}$ & $-5.19(0.88)^{\star}$ & $-2.77(1.10)^{\star}$ \\
\hline Upper Extremities SF^^ & $-0.86(0.40)^{\star}$ & $-3.19(0.76)^{\star}$ & $1.29(1.29)$ & $-1.56(0.44)^{\star}$ & $-3.43(1.00)^{\star}$ & $0.56(1.27)$ \\
\hline
\end{tabular}

This article is protected by copyright. All rights reserved. 
Lower Extremities CAT^

Lower Extremities SF^

$-0.41(0.38) \quad-2.62(0.72)^{*}$

0.35 (1.22)

$-1.41(0.43)^{\star}$

$-4.33(0.98)^{\star}$

$-1.41(1.24)$

Note: *Denotes that change significantly differs from $0(\mathrm{p}<.05)$; Higher scores indicate worse HRQOL unless indicated. ${ }^{\prime}$ Indicates that

measure is reverse scored (i.e., higher scores indicate better HRQOL)

This article is protected by copyright. All rights reserved. 


\section{COPYRIGHT TRANSFER AGREEMENT}

Date: April 1, 2019

Contributor name: Nicholas R. Boileau

Contributor address: 2800 Plymouth Road, Ann Arbor, MI, 48109

Manuscript number: MDS - 19 - 0114.R1

Re: Manuscript entitled: HDQLIFE and Neuro-QoL Physical Function measures:

for publication in: Movement Disorders (the "Journal")

Published by Wiley on behalf of The International Parkinson and Movement Disorder Society (the "Owner")

Dear Contributor(s):

Thank you for submitting your Contribution for publication. In order to expedite the editing and publishing process and enable the Owner to disseminate your Contribution to the fullest extent, we need to have this Copyright Transfer Agreement executed. If the Contribution is not accepted for publication, or if the Contribution is subsequently rejected, this Agreement shall be null and void. Publication cannot proceed without a signed copy of this Agreement.

\section{A. COPYRIGHT}

The Contributor assigns to the Owner, during the full term of copyright and any extensions or renewals, all copyright in and to the Contribution, and all rights therein, including but not limited to the right to reproduce, publish, republish, transmit, sell, transfer, distribute, and otherwise use the Contribution in whole or in part in electronic and print editions of the Journal and in derivative works throughout the world, in all languages and in all media of expression now known or later developed, and to license or permit others to do so.

\section{B. RETAINED RIGHTS}

Notwithstanding the above, the Contributor or, if applicable, the Contributor's employer, retains all proprietary rights other than copyright, such as patent rights, in any process, procedure or article of manufacture described in the Contribution. This reservation of rights does not affect or limit the rights assigned to Owner in Section A.

\section{PERMITTED USES BY CONTRIBUTOR}

1. License. The Owner grants to Contributor a non-exclusive, non-transferable and limited license to reproduce and distribute copies of the print or electronic "preprints" of the unpublished Contribution, in the original form submitted to the Journal prior to the peer review process, solely to colleagues within the Contributor's nonprofit organization or educational institution. The Contributor shall make no more than 100 printed copies of the preprints in any calendar year. Such preprints may be posted as electronic files on the Contributor's own personal website, on the Contributor's internal intranet at Contributor's nonprofit organization or educational institution, or on a secure external website at the Contributor's nonprofit organization or educational institution, provided that access is limited to employees and/or students at Contributor's non-profit organization or educational institution. Contributor shall not charge a fee for any 
preprints, and Contributor's use under this Section C shall not be for any commercial purpose, or for any systematic external distribution (e.g., posting on a listserve, public website, database connected to a public access server, or automated delivery system). The license grant in this Section does not apply to for-profit corporations, and any proposed use outside of the scope of this Section $\mathrm{C}$ must be pre-approved in writing by the Owner. The rights granted to Contributor under this Section $\mathrm{C}$ do not include reproduction, distribution or any other use of rating scales, videos or other audiovisual materials associated with the Contribution.

2. Required Citation. Prior to publication, the Contributor must provide full credit and acknowledgement of the Journal in all preprints in the following format: This is a preprint of an article accepted for publication in [Journal Title], Copyright $\mathbb{C}$ [year] The International Parkinson and Movement Disorder Society. After publication, the Contributor must provide a citation to the Journal in all preprints in the following format: This is a preprint of an article that was published in [Journal title]: (Title of Article, Contributor, Journal Title and Volume/ Issue, Copyright $\mathbb{C}$ [year] The International Parkinson and Movement Disorder Society). An electronic link must be provided to the Journal's website, located at http://www.interscience. Wiley.com. The Contributor agrees not to update the preprint or replace it with the published version of the Contribution.

3. Accepted Version. Re-use of the accepted and peer-reviewed (but not the final typeset published) version of the Contribution (the "Accepted Version") is not permitted under this Agreement. There are separate arrangements with certain funding agencies governing reuse of the Accepted Version. Additional terms apply if the Contributor receives or received funding from these agencies. The details of those relationships, and other offerings allowing open web use, are set forth at the following website: http://www.wiley.com/go/ funderstatement.

4. Additional Terms for Certain Funders. Certain funders, including the NIH, members of the Research Councils UK (RCUK) and Wellcome Trust require deposit of the Accepted Version in a public repository after an embargo period. Details of funding arrangements are set out at the following website: http://www.wiley.com/go/funderstatement. Additional terms may be applicable. Please contact the production editor for the journal at MDSprod@wiley.com if you have additional funding requirements.

If any Contributor receiving funds from applicable sources does not choose the Owner's OnlineOpen option, the Contributor will be allowed to self-archive by depositing the Accepted Version in a public repository after the following applicable embargo period has expired, subject to further conditions imposed by the RCUK:

a. $\quad 12$ months from first publication online of the final published version of the Contribution for research funded by members of the Research Councils UK (RCUK) other than The Economic and Social Research Council (ESRC) and the Arts and Humanities Research Council (AHRC); or

b. $\quad 24$ months from first publication online of the final published version of the Contribution for research funded by ESRC or AHRC.

5. Additional Terms for Certain Institutions. Wiley has arrangements with certain educational institutions to permit the deposit of the Accepted Version in the institutional repository after an embargo period. Details of such arrangements are set out at the following website:

http://olabout,wiley.com/WileyCDA/Section/id-406074.html . Additional terms may be applicable.

If any Contributor affiliated with these applicable educational institutions does not choose the Owner's OnlineOpen option, the Contributor will be allowed to self-archive by depositing the Accepted Version in the educational institution's repository after the following applicable embargo period has expired. See the following website for details: http://olabout. wiley.com/WileyCDA/Section/id-817011.html. 


\section{CONTRIBUTIONS OWNED BY EMPLOYER}

If the Contribution was written by the Contributor in the course of the Contributor's employment (as a "work-made-for-hire" in the course of employment), the Contribution is owned by the company/institution which must execute this Agreement (in addition to the Contributor's signature). In such case, the company/institution hereby assigns to the Owner, during the full term of copyright, all copyright in and to the Contribution for the full term of copyright throughout the world as specified in Section A above.

\section{E. GOVERNMENT CONTRACTS}

In the case of a Contribution prepared under U.S. Government contract or grant, the U.S. Government may reproduce, without charge, all or portions of the Contribution and may authorize others to do so, for official U.S. Government purposes only, if the U.S. Government contract or grant so requires. (U.S. Government, U.K. Government, and other government employees: see notes at end.)

\section{F. CONTRIBUTOR'S REPRESENTATIONS}

The Contributor represents that the Contribution is the Contributor's original work, all individuals identified as Contributors actually contributed to the Contribution, and all individuals who contributed are included. The Contribution is submitted only to this Journal and has not been published before. (If excerpts from copyrighted works owned by third parties are included, the Contributor will obtain written permission from the copyright owners for all uses as set forth in the Journal's Instructions for Contributors, and show credit to the sources in the Contribution.) The Contributor also warrants that the Contribution contains no libelous or unlawful statements, does not infringe upon the rights (including without limitation the copyright, patent or trademark rights) or the privacy of others, or contain material or instructions that might cause harm or injury. Upon request, Contributor will provide the data or will cooperating fully in obtaining and providing the data on which the Contribution is based for examination by the editors or their assignees.

\section{G. FINANCIAL DISCLOSURES}

The Contributor certifies that his/her financial and material support for this research and work, regardless of date, is clearly identified on Exhibit A to this Agreement. The Contributor has also identified on Exhibit A, all other support unrelated to this research, covering the past year from the date of submission (e.g., grants, advisory boards, employment, consultancies, contracts, honoraria, royalties, expert testimony, partnerships, or stock ownership in medically-related fields).

\section{H. VIDEO AND PHOTOGRAPHY CONSENT}

In the event that the Contribution includes, discloses or incorporates any content (including, without limitation, any video clip or photograph) which identifies any individual patient(s) ("patient identifiable content"), the Contributor obtained from such patient(s) written consent to such inclusion, disclosure or incorporation and that this consent fully complies with all legal requirements, including without limitation, all of the requirements of the laws of the jurisdiction(s) to which the patient(s) and the patient(s)' physician are subject, including the United States Health Insurance Portability and Accountability Act of 1996 ("HIPAA") if applicable. The Contributor hereby certifies that, if the patient consent form is in a language other than English, such consent form meets all of the requirements set forth in the Instructions to Authors. In addition, the Contributor hereby confirms that he/she obtained from patient(s) written consent to use the patient identifiable content in both print and online (i.e., internet/web-based) publication formats. The Contributor further certifies that the person executing any such patient consent form, to the best of his/her knowledge, had legal capacity under applicable law to execute the form on behalf of the patient. 


\section{ACKNOWLEDGEMENTS}

The Contributor should obtain written permission from all individuals named in the acknowledgement since readers may infer their endorsement of data and conclusions. The Contributor certifies that all individuals named in the acknowledgement section have provided written permission to be named.

\section{J. MiSCELLANEOUS}

This Agreement may be amended or modified only in a writing executed by both parties. The waiver or failure of any party to exercise any rights under this Agreement shall not be deemed a waiver or other limitation of any other right or any future right. This Agreement shall inure to the benefit of, and shall be binding upon, the parties, their respective successors and permitted assigns. This Agreement may be executed in two (2) or more counterparts, each of which shall be an original and all of which taken together shall constitute one and the same agreement. Executed copies of this Agreement may be delivered by facsimile transmission, pdf/email or other comparable electronic means. If for any reason any provision of this Agreement shall be deemed by a court of competent jurisdiction to be legally invalid or unenforceable, the validity, legality and enforceability of the remainder of this Agreement shall not be affected and such provision shall be deemed modified to the minimum extent necessary to make such provision consistent with applicable law and, in its modified form, such provision shall then be enforceable and enforced. The parties agree to do such further acts and to execute and deliver such additional agreements and instruments from time to time as either may at any time reasonably request in order to assure and confirm unto such requesting party the rights, powers and remedies conferred in the Agreement. This Agreement, including any exhibits attached hereto, contains the entire agreement and understanding of the parties with respect to the subject matter hereof, and supersedes all prior agreements, negotiations, representations and proposals, written and oral, relating thereto.

All Contributors must sign below. Contributors must check one box except that NIH grantees should check both Contributor-owned work and the NIH grantee box. If your Contribution was written during the course of employment, your employer must also sign where indicated.

Please send your original completed and signed forms by fax or email a scanned copy to the Journal production editor. For production editor contact details please visit the Journal's online author guidelines. Do not send in hard copies of these forms.

$[\mathrm{X}]$ Contributor-owned work

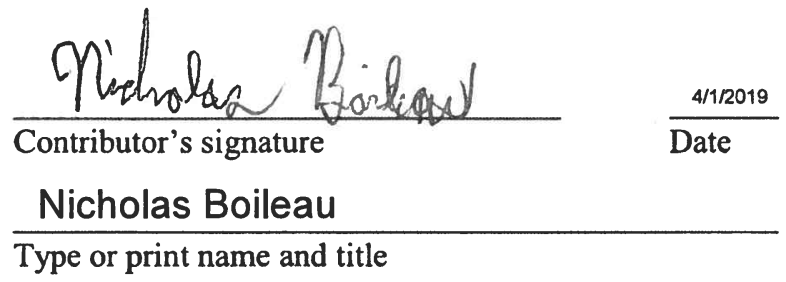

$\overline{\text { Co-Contributor's signature }} \overline{\text { Date }}$

Type or print name and title 
] Company/Institution-owned

Work (made-for-hire in the

Course of employment)

$\overline{\text { Company or Institution (Employer-for-Hire) }} \overline{\text { Date }}$

Authorized signature of Employer

Date

Contributor's signature

Date

Type or print name and title

ATTACH ADDITIONAL SIGNATURE PAGES AS NECESSARY

\section{[_] U.S. Government work}

Note to U.S. Government Employees

A contribution prepared by a U.S. federal government employee as part of the employee's official duties, or which is an official U.S. Government publication, is called a "U.S. Government work", and is in the public domain in the United States. In such case, Paragraph A.1 will not apply but the Contributor must type his/her name (in the Contributor's signature line) above. Contributor acknowledges that the Contribution will be published in the United States and other countries. If the Contribution was not prepared as part of the employee's duties or is not an official U.S. Government publication, it is not a U.S. Government work.

\section{[_] U.K. Government work (Crown Copyright)}

Note to U.K. Government Employees

The rights in a contribution prepared by an employee of a UK government department, agency or other Crown body as part of his/her official duties, or which is an official government publication, belong to the Crown. Contributors must ensure they comply with departmental regulations and submit the appropriate authorisation to publish. If your status as a government employee legally prevents you from signing this Agreement, please contact the Journal production editor.

\section{$[\mathrm{X}$ ] Other}

Including Other Government work or Non-Governmental Organisation work Note to Non-U.S., Non-U.K. Government Employees or Non-Governmental Organisation Employees If your status as a government or non-governmental organisation employee legally prevents you from signing this Agreement, please contact the Journal production editor. 
Exhibit A

\section{Financial Disclosure}

The Contributor has received financial and material support for this research and work regardless of date from the following sources:

Name: National Institutes of Health $(\mathrm{NIH})$

Address: 9000 Rockville Pike, Bethesda, MD 20892

Type of support: Grant

This material will be printed with the published article.

In the past year from the date of submission, the Contributor has also received the following support unrelated to this research (e.g., grants, advisory boards, employment, consultancies, contracts, honoraria, royalties, expert testimony, partnerships, or stock ownership in medically-related fields):

Name: National Institute of Nursing Research

Address: 31 Center Drive Room 6B10, Bethesda, MD 20892

Type of support: Grant

This material will be posted on the journal website and may be printed at the Editors' discretion.

\section{ATTACH ADDITIONAL INFORMATION AS NECESSARY}


Additional Funding Support:

In the past year from the date of submission, the Contributor has also received the following support unrelated to this research:

Name: $\underline{\mathrm{CHDI}}$ Foundation

Address: $3507^{\text {th }}$ Avenue $\# 601$, New York, NY 10001

Type of Support: Grant

Name: Craig $\mathrm{H}$. Neilsen Foundation

Address: 16830 Ventura Blvd, Suite 352. Encino, CA 91436

Type of Support: Grant

Name: General Dynamics Information Technology (GDIT) - a subcontract from the Department of Defense (Department of Army)

Address: 3211 Jermantown Road, Fairfax, VA 22030

Type of Support: Grant

This article is protected by copyright. All rights reserved. 


\section{COPYRIGHT TRANSFER AGREEMENT}

Date: April 1, 2019

Contributor name:

KELVIN CHOU

Contributor address: 2301 COMMONWEACTI BLVID INN ARBOR, MI 48105

Manuscript number: MDS - 19 - 0114.R1

Re: Manuscript entitled: HDQLIFE and Neuro-QoL Physical Function measures:

for publication in: Movement Disorders (the "Journal")

Published by Wiley on behalf of The International Parkinson and Movement Disorder Society (the "Owner")

Dear Contributor(s):

Thank you for submitting your Contribution for publication. In order to expedite the editing and publishing process and enable the Owner to disseminate your Contribution to the fullest extent, we need to have this Copyright Transfer Agreement executed. If the Contribution is not accepted for publication, or if the Contribution is subsequently rejected, this Agreement shall be null and void. Publication cannot proceed without a signed copy of this Agreement.

\section{A. COPYRIGHT}

The Contributor assigns to the Owner, during the full term of copyright and any extensions or renewals, all copyright in and to the Contribution, and all rights therein, including but not limited to the right to reproduce, publish, republish, transmit, sell, transfer, distribute, and otherwise use the Contribution in whole or in part in electronic and print editions of the Journal and in derivative works throughout the world, in all languages and in all media of expression now known or later developed, and to license or permit others to do so.

\section{B. RETAINED RIGHTS}

Notwithstanding the above, the Contributor or, if applicable, the Contributor's employer, retains all proprietary rights other than copyright, such as patent rights, in any process, procedure or article of manufacture described in the Contribution. This reservation of rights does not affect or limit the rights assigned to Owner in Section A.

\section{PERMITTED USES BY CONTRIBUTOR}

1. License. The Owner grants to Contributor a non-exclusive, non-transferable and limited license to reproduce and distribute copies of the print or electronic "preprints" of the unpublished Contribution, in the original form submitted to the Journal prior to the peer review process, solely to colleagues within the Contributor's nonprofit organization or educational institution. The Contributor shall make no more than 100 printed copies of the preprints in any calendar year. Such preprints may be posted as electronic files on the Contributor's own personal website, on the Contributor's internal intranet at Contributor's nonprofit organization or educational institution, or on a secure external website at the Contributor's nonprofit organization or educational institution, provided that access is limited to employees and/or students at Contributor's non-profit organization or educational institution. Contributor shall not charge a fee for any 
preprints, and Contributor's use under this Section C shall not be for any commercial purpose, or for any systematic external distribution (e.g., posting on a listserve, public website, database connected to a public access server, or automated delivery system). The license grant in this Section does not apply to for-profit corporations, and any proposed use outside of the scope of this Section $\mathbf{C}$ must be pre-approved in writing by the Owner. The rights granted to Contributor under this Section $C$ do not include reproduction, distribution or any other use of rating scales, videos or other audiovisual materials associated with the Contribution.

2. Required Citation. Prior to publication, the Contributor must provide full credit and acknowledgement of the Journal in all preprints in the following format: This is a preprint of an article accepted for publication in [Journal Title], Copyright 0 [year] The International Parkinson and Movement Disorder Society. After publication, the Contributor must provide a citation to the Joumal in all preprints in the following format: This is a preprint of an article that was published in [Journal title]: (Tit)e of Article, Contributor, Journal Title and Volume/ Issue, Copyright 0 [year] The Intemational Parkinson and Movement Disorder Society). An electronic link must be provided to the Journal's website, located at hutp: i/www:interscience. Wiley.com. The Contributor agrees not to update the preprint or replace it with the published version of the Contribution.

3. Accepted Version. Rc-use of the accepted and peer-reviewed (but not the final typeset published) version of the Contribution (the "Accepted Version") is not permitted under this Agreement. There are separate arrangements with certain funding agencies governing reuse of the Accepted Version. Additional terms apply if the Contributor receives or received funding from these agencies. The details of those relationships, and other offerings allowing open web use, are set forth at the following website: http://www.wiley.com/go' funderstatement.

4. Additional Terms for Certain Funders. Certain funders, including the NIH, members of the Research Councils UK (RCUK) and Wellcome Trust require deposit of the Accepted Version in a public repository after an embargo period. Details of funding arrangements are set out at the following website: http://www.wiley.com'go/funderstatement. Additional terms may be applicable. Please contact the production editor for the joumal at MDSprod@wiley.com if you have additional funding requirements.

If any Contributor receiving funds from applicable sources does not choose the Owner's OnlineOpen option, the Contributor will be allowed to self-archive by depositing the Accepted Version in a public repository after the following applicable embargo period has expired, subject to further conditions imposed by the RCUK:

a. 12 months from first publication online of the final published version of the Contribution for research funded by members of the Rescarch Councils UK (RCUK) other than The Economic and Social Research Council (ESRC) and the Arts and Humanities Research Council (AHRC); or

b. $\quad 24$ months from first publication online of the final published version of the Contribution for research funded by ESRC or AHRC.

5. Additional Terms for Certain Institutions. Wiley has arrangements with certain educational institutions to permit the deposit of the Accepted Version in the institutional repository after an embargo period. Details of such arrangements are set out at the following website: http://olabout.wiley.com/WileyCDA/Section/id-406074.html . Additional terms may be applicable.

If any Contributor affiliated with these applicable educational institutions does not choose the Owner's OnlineOpen option, the Contributor will be allowed to self-archive by depositing the Accepted Version in the educational institution's repository after the following applicable embargo period has expired. See the following website for details: htup://olabout.wiley.com/WileyCDA/Section/id-817011.html. 


\section{CONTRIBUTIONS OWNED BY EMPLOYER}

If the Contribution was written by the Contributor in the course of the Contributor's employment (as a "work-made-for-hire" in the course of employment), the Contribution is owned by the company/institution which must execute this Agreement (in addition to the Contributor's signature). In such case, the company/instinution hereby assigns to the Owner, during the full term of copyright, all copyright in and to the Contribution for the full term of copyright throughout the world as specified in Section A above.

\section{E. GOVERNMENT CONTRACTS}

In the case of a Contribution prepared under U.S. Govemment contract or grant, the U.S. Government may reproduce, without charge, all or portions of the Contribution and may authorize others to do so, for official U.S. Government purposes only, if the U.S. Government contract or grant so requires. (U.S. Government, U.K. Government, and other government employees: see notes at end.)

\section{F. CONTRIBUTOR'S REPRESENTATIONS}

The Contributor represents that the Contribution is the Contributor's original work, all individuals identified as Contributors actually contributed to the Contribution, and all individuals who contributed are included. The Contribution is submitted only to this Joumal and has not been published before. (If excerpts from copyrighted works owned by third parties are included, the Contributor will obtain written permission from the copyright owners for all uses as set forth in the Joumal's Instructions for Contributors, and show credit to the sources in the Contribution.) The Contributor also warrants that the Contribution contains no libelous or unlawful statements, does not infringe upon the rights (including without limitation the copyright, patent or trademark rights) or the privacy of others, or contain material or instructions that might cause harm or injury. Upon request, Contributor will provide the data or will cooperating fully in obtaining and providing the data on which the Contribution is based for examination by the editors or their assignees.

\section{G. FINANCIAL DISCLOSURES}

The Contributor certifies that his/her financial and material support for this research and work, regardless of date, is clearly identified on Exhibit A to this Agreement. The Contributor has also identified on Exhibit A, all other support unrelated to this research, covering the past year from the date of submission (e.g., grants, advisory boards, employment, consultancies, contracts, honoraria, royalties, expert testimony, partnerships, or stock ownership in medically-related fields).

\section{H. VIDEO AND PHOTOGRAPHY CONSENT}

In the event that the Contribution includes, discloses or incorporates any content (including, without limitation, any video clip or photograph) which identifies any individual patient(s) ("patient identifiable content"), the Contributor obtained from such patient(s) written consent to such inclusion, disclosure or incorporation and that this consent fully complies with all legal requirements, including without limitation, all of the requirements of the laws of the jurisdiction(s) to which the patient(s) and the patient(s)' physician are subject, including the Linited States Health Insurance Portability and Accountability Act of 1996 ("HIPAA") if applicable. The Contributor hereby certifies that, if the patient consent form is in a language other than English, such consent form meets all of the requirements set forth in the Instructions to Authors. In addition, the Contributor hereby confirms that he/she obtained from patient(s) written consent to use the patient identifiable content in both print and online (i.e., internet/web-based) publication formats. The Contributor further certifies that the person executing any such patient consent form, to the best of his/her knowledge, had legal capacity under applicable law to execute the form on behalf of the paticnt. 


\section{ACKNOWLEDGEMENTS}

The Contributor should obtain written permission from all individuals named in the acknowledgement since readers may infer their endorsement of data and conclusions. The Contributor certifies that all individuals named in the acknowledgement section have provided written permission to be named.

\section{J. MisCELlaneOUS}

This Agreement may be amended or modified only in a writing executed by both parties. The waiver or failure of any party to exercise any rights under this Agreement shall not be deemed a waiver or other limitation of any other right or any future right. This Agreement shall inure to the benefit of, and shall be binding upon, the parties, their respective successors and permitted assigns. This Agreement may be executed in two (2) or more counterparts, each of which shall be an original and all of which taken together shall constitute one and the same agreement. Executed copies of this Agreement may be delivered by facsimile transmission, pdffemail or other comparable electronic means. If for any reason any provision of this Agreement shall be deemed by a court of competent jurisdiction to be legally invalid or unenforceable, the validity, legality and enforceability of the remainder of this Agreement shall not be affected and such provision shall be decmed modified to the minimum extent necessary to make such provision consistent with applicable law and, in its modified form, such provision shall then be enforceable and enforced. The parties agree to do such further acts and to execute and deliver such additional agreements and instruments from time to time as cither may at any time reasonably request in order to assure and confirm unto such requesting party the rights, powers and remedies conferred in the Agreement. This Agreement, including any exhibits attached hereto, contains the entire agreement and understanding of the parties with respect to the subject matter hereof, and supersedes all prior agreements, negotiations, representations and proposals, written and oral, relating thereto.

All Contributors must sign below. Contributors must check one box except that NIH grantees should check both Contributor-owned work and the NIH grantee box. If your Contribution was written during the course of employment, your employer must also sign where indicated.

Please send your original completed and signed forms by fax or email a scanned copy to the Journal production editor. For production editor contact details please visit the Journal's online author guidelines. Do not send in hard copies of these forms.

Contributor-owned work

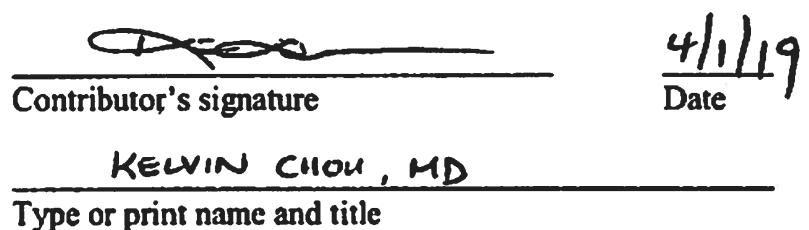

$\overline{\text { Co-Contributor's signature }} \overline{\text { Date }}$

Type or print name and title 
Company/Institution-owned Work (made-for-hire in the Course of employment)

\author{
Company or Institution (Employer-for-Hire) Date
}

Authorized signature of Employer

Date

Contributor's signature

$\overline{\text { Date }}$

Type or print name and title

\section{ATTACH ADDITIONAL SIGNATURE PAGES AS NECESSARY}

\section{[__ ] U.S. Government work}

Note 10 U.S. Government Employees

A contribution prepared by a U.S. federal government employee as part of the employee's official duties, or which is an official U.S. Government publication, is called a "U.S. Government work", and is in the public domain in the United States. In such case. Paragraph A.I will not apply but the Contributor must type his/her name (in the Contributor's signature line) above. Contributor acknowledges that the Contribution will be published in the United States and other countries. If the Contribution was not prepared as part of the employee's duties or is not an official U.S. Government publication, it is not a U.S. Government work.

\section{L_] U.K. Government work (Crown Copyright)}

Note to U.K. Government Employees

The rights in a contribution prepared by an employee of a UK government department, agency or other Crown body as part of hisher official duties, or which is an official government publication, belong to the Crown. Contributors must ensure they comply with departmental regulations and submit the appropriate authorisation to publish. IS your status as a government employee legally prevents you from signing this Agreement, please contact the Journal production editor.

\section{L_] Other}

Including Other Government work or Non-Governmental Organisation work Note to Non-U.S., Non-U.K. Government Employees or Non-Governmental Organisation Employees If your status as a government or non-governmental organisation employee legally prevents you from signing this Agreement, please contact the Journal production editor. 


\section{KeLVIN CHOU}

\section{Exhibit A}

\section{Financial Disclosure}

The Contributor has received financial and material support for this research and work regardless of date from the following sources:

None

In the past year from the date of submission, the Contributor has also received the following support unrelated to this research (e.g., grants, advisory boards, employment, consultancies, contracts, honoraria, royalties, expert testimony, partnerships, or stock ownership in medically-related fields):

Grants:

NIH (NS091856-01, NS10061102, NS107158)

Parkinson Study Group (STEADY-PD III, SURE-PD3, NILO-PD)

Cavion

Eli Lilly

Consulting:

Accordant

Boston Scientific

Sunovion Pharmaceuticals

Royalties:

UpToDate

Springer Publishing 


\section{COPYRIGHT TRANSFER AGREEMENT}

Date: April 1, 2019

Contributor name: Jennifer A. Miner

Contributor address: 2800 Plymouth Rd., Building NCRC B14, Room G217, Ann Arbor, MI 48109-2800

Manuscript number: MDS - 19 - 0114.R1

Re: Manuscript entitled: $\begin{aligned} & \text { HDQLIFE and Neuro-QOL Physical Function measures: } \\ & \text { Longitudinal validity in persons with Huntington disease }\end{aligned}$ (the "Contribution")

for publication in: Movement Disorders (the "Journal")

Published by Wiley on behalf of The International Parkinson and Movement Disorder Society (the "Owner”)

Dear Contributor(s):

Thank you for submitting your Contribution for publication. In order to expedite the editing and publishing process and enable the Owner to disseminate your Contribution to the fullest extent, we need to have this Copyright Transfer Agreement executed. If the Contribution is not accepted for publication, or if the Contribution is subsequently rejected, this Agreement shall be null and void. Publication cannot proceed without a signed copy of this Agreement.

\section{A. COPYRIGHT}

The Contributor assigns to the Owner, during the full term of copyright and any extensions or renewals, all copyright in and to the Contribution, and all rights therein, including but not limited to the right to reproduce, publish, republish, transmit, sell, transfer, distribute, and otherwise use the Contribution in whole or in part in electronic and print editions of the Journal and in derivative works throughout the world, in all languages and in all media of expression now known or later developed, and to license or permit others to do so.

\section{B. RETAINED RIGHTS}

Notwithstanding the above, the Contributor or, if applicable, the Contributor's employer, retains all proprietary rights other than copyright, such as patent rights, in any process, procedure or article of manufacture described in the Contribution. This reservation of rights does not affect or limit the rights assigned to Owner in Section A.

\section{PERMITTED USES BY CONTRIBUTOR}

1. License. The Owner grants to Contributor a non-exclusive, non-transferable and limited license to reproduce and distribute copies of the print or electronic "preprints" of the unpublished Contribution, in the original form submitted to the Journal prior to the peer review process, solely to colleagues within the Contributor's nonprofit organization or educational institution. The Contributor shall make no more than 100 printed copies of the preprints in any calendar year. Such preprints may be posted as electronic files on the Contributor's own personal website, on the Contributor's internal intranet at Contributor's nonprofit organization or educational institution, or on a secure external website at the Contributor's nonprofit organization or educational institution, provided that access is limited to employees and/or students at Contributor's non-profit organization or educational institution. Contributor shall not charge a fee for any 
preprints, and Contributor's use under this Section C shall not be for any commercial purpose, or for any systematic external distribution (e.g., posting on a listserve, public website, database connected to a public access server, or automated delivery system). The license grant in this Section does not apply to for-profit corporations, and any proposed use outside of the scope of this Section $\mathrm{C}$ must be pre-approved in writing by the Owner. The rights granted to Contributor under this Section $\mathrm{C}$ do not include reproduction, distribution or any other use of rating scales, videos or other audiovisual materials associated with the Contribution.

2. Required Citation. Prior to publication, the Contributor must provide full credit and acknowledgement of the Journal in all preprints in the following format: This is a preprint of an article accepted for publication in [Journal Title], Copyright $(\mathcal{C}$ [year] The International Parkinson and Movement Disorder Society. After publication, the Contributor must provide a citation to the Journal in all preprints in the following format: This is a preprint of an article that was published in [Journal title]: (Title of Article, Contributor, Journal Title and Volume/ Issue, Copyright $\mathbb{C}$ [year] The International Parkinson and Movement Disorder Society). An electronic link must be provided to the Journal's website, located at hetp:/hwww. interscience. Wiley com. The Contributor agrees not to update the preprint or replace it with the published version of the Contribution.

3. Accepted Version. Re-use of the accepted and peer-reviewed (but not the final typeset published) version of the Contribution (the "Accepted Version") is not permitted under this Agreement. There are separate arrangements with certain funding agencies governing reuse of the Accepted Version. Additional terms apply if the Contributor receives or received funding from these agencies. The details of those relationships, and other offerings allowing open web use, are set forth at the following website: http://www.wiley.com/go/ funderstatement.

4. Additional Terms for Certain Funders. Certain funders, including the NIH, members of the Research Councils UK (RCUK) and Wellcome Trust require deposit of the Accepted Version in a public repository after an embargo period. Details of funding arrangements are set out at the following website:

hitp:/www wilcy compo/funderstatement. Additional terms may be applicable. Please contact the production editor for the journal at MDSprodar wiley com if you have additional funding requirements.

If any Contributor receiving funds from anplicable sources does not choose the Owner's OnlineOpen ontion, the Contributor will be allowed to self-archive by depositing the Accepted Version in a public repository after the following applicable embargo period has expired, subject to further conditions imposed by the RCUK:

a. $\quad 12$ months from first publication online of the final published version of the Contribution for research funded by members of the Research Councils UK (RCUK) other than The Economic and Social Research Council (ESRC) and the Arts and Humanities Research Council (AHRC); or

b. $\quad 24$ months from first publication online of the final published version of the Contribution for research funded by ESRC or AHRC.

5. Additional Terms for Certain Institutions. Wiley has arrangements with certain educational institutions to permit the deposit of the Accepted Version in the institutional repository after an embargo period. Details of such arrangements are set out at the following website:

http://olabout.wiley.com/WileyCDA/Section/id-406074, html . Additional terms may be applicable.

If any Contributor affiliated with these applicable educational institutions does not choose the Owner's OnlineOpen option, the Contributor will be allowed to self-archive by depositing the Accepted Version in the educational institution's repository after the following applicable embargo period has expired. See the following website for details: http://about wiley.com/WileyCDA/Section/id-817011.htm/. 


\section{CONTRIBUTIONS OWNED BY EMPLOYER}

If the Contribution was written by the Contributor in the course of the Contributor's employment (as a "work-made-for-hire" in the course of employment), the Contribution is owned by the company/institution which must execute this Agreement (in addition to the Contributor's signature). In such case, the company/institution hereby assigns to the Owner, during the full term of copyright, all copyright in and to the Contribution for the full term of copyright throughout the world as specified in Section A above.

\section{E. GOVERNMENT CONTRACTS}

In the case of a Contribution prepared under U.S. Government contract or grant, the U.S. Government may reproduce, without charge, all or portions of the Contribution and may authorize others to do so, for official U.S. Government purposes only, if the U.S. Government contract or grant so requires. (U.S. Government, U.K. Government, and other government employees: see notes at end.)

\section{F. CONTRIBUTOR'S REPRESENTATIONS}

The Contributor represents that the Contribution is the Contributor's original work, all individuals identified as Contributors actually contributed to the Contribution, and all individuals who contributed are included. The Contribution is submitted only to this Journal and has not been published before. (If excerpts from copyrighted works owned by third parties are included, the Contributor will obtain written permission from the copyright owners for all uses as set forth in the Journal's Instructions for Contributors, and show credit to the sources in the Contribution.) The Contributor also warrants that the Contribution contains no libelous or unlawful statements, does not infringe upon the rights (including without limitation the copyright, patent or trademark rights) or the privacy of others, or contain material or instructions that might cause harm or injury. Upon request, Contributor will provide the data or will cooperating fully in obtaining and providing the data on which the Contribution is based for examination by the editors or their assignees.

\section{G. FINANCIAL DISCLOSURES}

The Contributor certifies that his/her financial and material support for this research and work, regardless of date, is clearly identified on Exhibit A to this Agreement. The Contributor has also identified on Exhibit A, all other support unrelated to this research, covering the past year from the date of submission (e.g., grants, advisory boards, employment, consultancies, contracts, honoraria, royalties, expert testimony, partnerships, or stock ownership in medically-related fields).

\section{H. VIDEO AND PHOTOGRAPHY CONSENT}

In the event that the Contribution includes, discloses or incorporates any content (including, without limitation, any video clip or photograph) which identifies any individual patient(s) ("patient identifiable content"), the Contributor obtained from such patient(s) written consent to such inclusion, disclosure or incorporation and that this consent fully complies with all legal requirements, including without limitation, all of the requirements of the laws of the jurisdiction(s) to which the patient(s) and the patient(s)' physician are subject, including the United States Health Insurance Portability and Accountability Act of 1996 ("HIPAA") if applicable. The Contributor hereby certifies that, if the patient consent form is in a language other than English, such consent form meets all of the requirements set forth in the Instructions to Authors. In addition, the Contributor hereby confirms that he/she obtained from patient(s) written consent to use the patient identifiable content in both print and online (i.e., internet/web-based) publication formats. The Contributor further certifies that the person executing any such patient consent form, to the best of his/her knowledge, had legal capacity under applicable law to execute the form on behalf of the patient. 


\section{ACKNOWLEDGEMENTS}

The Contributor should obtain written permission from all individuals named in the acknowledgement since readers may infer their endorsement of data and conclusions. The Contributor certifies that all individuals named in the acknowledgement section have provided written permission to be named.

\section{J. MISCELLANEOUS}

This Agreement may be amended or modified only in a writing executed by both parties. The waiver or failure of any party to exercise any rights under this Agreement shall not be deemed a waiver or other limitation of any other right or any future right. This Agreement shall inure to the benefit of, and shall be binding upon, the parties, their respective successors and permitted assigns. This Agreement may be executed in two (2) or more counterparts, each of which shall be an original and all of which taken together shall constitute one and the same agreement. Executed copies of this Agreement may be delivered by facsimile transmission, pdf/email or other comparable electronic means. If for any reason any provision of this Agreement shall be deemed by a court of competent jurisdiction to be legally invalid or unenforceable, the validity, legality and enforceability of the remainder of this Agreement shall not be affected and such provision shall be deemed modified to the minimum extent necessary to make such provision consistent with applicable law and, in its modified form, such provision shall then be enforceable and enforced. The parties agree to do such further acts and to execute and deliver such additional agreements and instruments from time to time as either may at any time reasonably request in order to assure and confirm unto such requesting party the rights, powers and remedies conferred in the Agreement. This Agreement, including any exhibits attached hereto, contains the entire agreement and understanding of the parties with respect to the subject matter hereof, and supersedes all prior agreements, negotiations, representations and proposals, written and oral, relating thereto.

All Contributors must sign below. Contributors must check one box except that NIH grantees should check both Contributor-owned work and the NIH grantee box. If your Contribution was written during the course of employment, your employer must also sign where indicated.

Please send your original completed and signed forms by fax or email a scanned copy to the Journal production editor. For production editor contact details please visit the Journal's online author guidelines.

Do not send in hard copies of these forms.
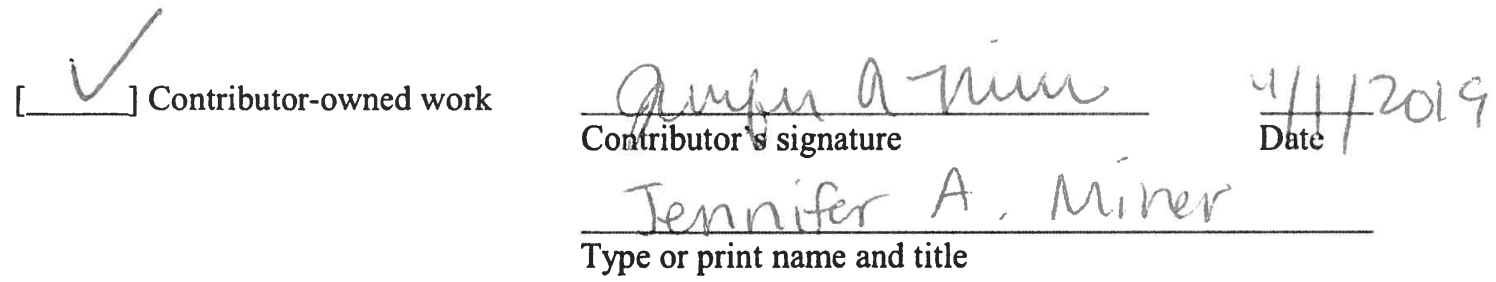

Co-Contributor's signature

Date

Type or print name and title 
] Company/Institution-owned

Work (made-for-hire in the

Course of employment)

\begin{tabular}{ll}
\hline Company or Institution (Employer-for-Hire) & $\overline{\text { Date }}$ \\
\hline Authorized signature of Employer & $\overline{\text { Date }}$ \\
\hline Contributor's signature & $\overline{\text { Date }}$
\end{tabular}

Type or print name and title

\section{ATTACH ADDITIONAL SIGNATURE PAGES AS NECESSARY}

\section{[_] U.S. Government work}

Note to U.S. Government Employees

A contribution prepared by a U.S. federal government employee as part of the employee's official duties, or which is an official U.S. Government publication, is called a "U.S. Government work", and is in the public domain in the United States. In such case, Paragraph A.1 will not apply but the Contributor must type his/her name (in the Contributor's signature line) above. Contributor acknowledges that the Contribution will be published in the United States and other countries. If the Contribution was not prepared as part of the employee's duties or is not an official U.S. Government publication, it is not a U.S. Government work.

\section{[_] U.K. Government work (Crown Copyright)}

Note to U.K. Government Employees

The rights in a contribution prepared by an employee of a UK government department, agency or other Crown body as part of his/her official duties, or which is an official government publication, belong to the Crown. Contributors must ensure they comply with departmental regulations and submit the appropriate authorisation to publish. If your status as a government employee legally prevents you from signing this Agreement, please contact the Journal production editor.

\section{$\checkmark$, Other}

Including Other Government work or Non-Governmental Organisation work Note to Non-U.S., Non-U.K. Government Employees or Non-Governmental Organisation Employees If your status as a government or non-governmental organisation employee legally prevents you from signing this Agreement, please contact the Journal production editor. 


\section{Exhibit A}

\section{Financial Disclosure}

The Contributor has received financial and material support for this research and work regardless of date from the following sources:

Name: National Institutes of Health

Address: 9000 Rockville Pike, Bethesda, MD, 20892

Type of support: Grant

This material will be printed with the published article.

In the past year from the date of submission, the Contributor has also received the following support unrelated to this research (e.g., grants, advisory boards, employment, consultancies, contracts, honoraria, royalties, expert testimony, partnerships, or stock ownership in medically-related fields):

Name: National Institutes of Health

Address: 9000 Rockville Pike, Bethesda, MD, 20892

Type of support: Grant

This material will be posted on the journal website and may be printed at the Editors' discretion.

\section{ATTACH ADDITIONAL INFORMATION AS NECESSARY}


In the past year from the date of submission, the Contributor has also received the following support unrelated to this research (e.g., grants, advisory boards, employment, consultancies, contracts, honoraria, royalties, expert testimony, partnerships, or stock ownership in medically-related fields):

Name: CHDI Foundation, Inc.

Address: 350 Seventh Ave., Suite 200, New York, NY 10001

Type of support: Contract

Name: Craig H. Neilsen Foundation

Address: 16830 Ventura Blvd., Suite 352, Encino, CA 91436

Type of support: Grant

Name: Goldfinch Bio

Address: 215 First Street, $4^{\text {th }}$ Floor, Cambridge, MA 02142

Type of support: Contract

Name: General Dynamics Information Technology

Address: 3211 Jermantown Road, Fairfax, VA 22030

Type of support: Contract

Name: Patient-Centered Outcomes Research Institute (PCORI)

Address: 1828 L St., NW, Suite 900, Washington, DC 20036

Type of support: Contract

Name: University of Michigan

Address: 325 E. Eisenhower Pkwy., Suite 100, Ann Arbor, MI 48108

Type of support: Employment

This material will be posted on the journal website and may be printed at the Editors' discretion.

This article is protected by copyright. All rights reserved. 


\section{COPYRIGHT TRANSFER AGREEMENT}

Date: April 1, 2019

Contributor name: Praveen Dayalu

Contributor address: 2301 Commonwealth Blvd, Rm 1025, Ann Arbor MI 48105

Manuscript number: MDS - 19 - 0114.R1

Re: Manuscript entitled: $\begin{aligned} & \text { HDQLIFE and Neuro-QoL Physical Function measures: } \\ & \text { Longitudinal validity in persons with Huntington disease }\end{aligned}$ (the "Contribution")

for publication in: Movement Disorders (the "Journal")

Published by Wiley on behalf of The International Parkinson and Movement Disorder Society (the "Owner")

Dear Contributor(s):

Thank you for submitting your Contribution for publication. In order to expedite the editing and publishing process and enable the Owner to disseminate your Contribution to the fullest extent, we need to have this Copyright Transfer Agreement executed. If the Contribution is not accepted for publication, or if the Contribution is subsequently rejected, this Agreement shall be null and void. Publication cannot proceed without a signed copy of this Agreement.

\section{A. COPYRIGHT}

The Contributor assigns to the Owner, during the full term of copyright and any extensions or renewals, all copyright in and to the Contribution, and all rights therein, including but not limited to the right to reproduce, publish, republish, transmit, sell, transfer, distribute, and otherwise use the Contribution in whole or in part in electronic and print editions of the Journal and in derivative works throughout the world, in all languages and in all media of expression now known or later developed, and to license or permit others to do so.

\section{B. RETAINED RIGHTS}

Notwithstanding the above, the Contributor or, if applicable, the Contributor's employer, retains all proprietary rights other than copyright, such as patent rights, in any process, procedure or article of manufacture described in the Contribution. This reservation of rights does not affect or limit the rights assigned to Owner in Section A.

\section{PERMITTED USES BY CONTRIBUTOR}

1. License. The Owner grants to Contributor a non-exclusive, non-transferable and limited license to reproduce and distribute copies of the print or electronic "preprints" of the unpublished Contribution, in the original form submitted to the Journal prior to the peer review process, solely to colleagues within the Contributor's nonprofit organization or educational institution. The Contributor shall make no more than 100 printed copies of the preprints in any calendar year. Such preprints may be posted as electronic files on the Contributor's own personal website, on the Contributor's internal intranet at Contributor's nonprofit organization or educational institution, or on a secure external website at the Contributor's nonprofit organization or educational institution, provided that access is limited to employees and/or students at Contributor's non-profit organization or educational institution. Contributor shall not charge a fee for any

This article is protected by copyright. All rights reserved. 
preprints, and Contributor's use under this Section C shall not be for any commercial purpose, or for any systematic external distribution (e.g., posting on a listserve, public website, database connected to a public access server, or automated delivery system). The license grant in this Section does not apply to for-profit corporations, and any proposed use outside of the scope of this Section $\mathrm{C}$ must be pre-approved in writing by the Owner. The rights granted to Contributor under this Section $\mathrm{C}$ do not include reproduction, distribution or any other use of rating scales, videos or other audiovisual materials associated with the Contribution.

2. Required Citation. Prior to publication, the Contributor must provide full credit and acknowledgement of the Journal in all preprints in the following format: This is a preprint of an article accepted for publication in [Journal Title], Copyright $\mathbb{C}$ [year] The International Parkinson and Movement Disorder Society. After publication, the Contributor must provide a citation to the Journal in all preprints in the following format: This is a preprint of an article that was published in [Journal title]: (Title of Article, Contributor, Journal Title and Volume/ Issue, Copyright $(\mathcal{C}$ [year] The International Parkinson and Movement Disorder Society). An electronic link must be provided to the Journal's website, located at http://www.interscience. Wiley.com. The Contributor agrees not to update the preprint or replace it with the published version of the Contribution.

3. Accepted Version. Re-use of the accepted and peer-reviewed (but not the final typeset published) version of the Contribution (the "Accepted Version") is not permitted under this Agreement. There are separate arrangements with certain funding agencies governing reuse of the Accepted Version. Additional terms apply if the Contributor receives or received funding from these agencies. The details of those relationships, and other offerings allowing open web use, are set forth at the following website: http://www.wiley.com/go/ funderstatement.

4. Additional Terms for Certain Funders. Certain funders, including the NIH, members of the Research Councils UK (RCUK) and Wellcome Trust require deposit of the Accepted Version in a public repository after an embargo period. Details of funding arrangements are set out at the following website:

http://www.wiley.com/go/funderstatement. Additional terms may be applicable. Please contact the production editor for the journal at MDSprod(a wiley.com if you have additional funding requirements.

If any Contributor recciving funds from applicable sources docs not choose the Owncr's OnlincOpen option, the Contributor will be allowed to self-archive by depositing the Accepted Version in a public repository after the following applicable embargo period has expired, subject to further conditions imposed by the RCUK:

a. $\quad 12$ months from first publication online of the final published version of the Contribution for research funded by members of the Research Councils UK (RCUK) other than The Economic and Social Research Council (ESRC) and the Arts and Humanities Research Council (AHRC); or

b. $\quad 24$ months from first publication online of the final published version of the Contribution for research funded by ESRC or AHRC.

5. Additional Terms for Certain Institutions. Wiley has arrangements with certain educational institutions to permit the deposit of the Accepted Version in the institutional repository after an embargo period. Details of such arrangements are set out at the following website: http://olabout.wiley.com/WileyCDA/Section/id-406074.html. Additional terms may be applicable.

If any Contributor affiliated with these applicable educational institutions does not choose the Owner's OnlineOpen option, the Contributor will be allowed to self-archive by depositing the Accepted Version in the educational institution's repository after the following applicable embargo period has expired. See the following website for details: http://olabout.wiley.com/WileyCDA/Section/id-817011.html. 


\section{CONTRIBUTIONS OWNED BY EMPLOYER}

If the Contribution was written by the Contributor in the course of the Contributor's employment (as a "work-made-for-hire" in the course of employment), the Contribution is owned by the company/institution which must execute this Agreement (in addition to the Contributor's signature). In such case, the company/institution hereby assigns to the Owner, during the full term of copyright, all copyright in and to the Contribution for the full term of copyright throughout the world as specified in Section A above.

\section{E. GOVERNMENT CONTRACTS}

In the case of a Contribution prepared under U.S. Government contract or grant, the U.S. Government may reproduce, without charge, all or portions of the Contribution and may authorize others to do so, for official U.S. Government purposes only, if the U.S. Government contract or grant so requires. (U.S. Government, U.K. Government, and other government employees: see notes at end.)

\section{F. CONTRIBUTOR'S REPRESENTATIONS}

The Contributor represents that the Contribution is the Contributor's original work, all individuals identified as Contributors actually contributed to the Contribution, and all individuals who contributed are included. The Contribution is submitted only to this Journal and has not been published before. (If excerpts from copyrighted works owned by third parties are included, the Contributor will obtain written permission from the copyright owners for all uses as set forth in the Journal's Instructions for Contributors, and show credit to the sources in the Contribution.) The Contributor also warrants that the Contribution contains no libelous or unlawful statements, does not infringe upon the rights (including without limitation the copyright, patent or trademark rights) or the privacy of others, or contain material or instructions that might cause harm or injury. Upon request, Contributor will provide the data or will cooperating fully in obtaining and providing the data on which the Contribution is based for examination by the editors or their assignees.

\section{G. FINANCIAL DISCLOSURES}

The Contributor certifies that his/her financial and material support for this research and work, regardless of date, is clearly identified on Exhibit A to this Agreement. The Contributor has also identified on Exhibit A, all other support unrelated to this research, covering the past year from the date of submission (e.g., grants, advisory boards, employment, consultancies, contracts, honoraria, royalties, expert testimony, partnerships, or stock ownership in medically-related fields).

\section{H. VIDEO AND PHOTOGRAPHY CONSENT}

In the event that the Contribution includes, discloses or incorporates any content (including, without limitation, any video clip or photograph) which identifies any individual patient(s) ("patient identifiable content"), the Contributor obtained from such patient(s) written consent to such inclusion, disclosure or incorporation and that this consent fully complies with all legal requirements, including without limitation, all of the requirements of the laws of the jurisdiction(s) to which the patient(s) and the patient(s)' physician are subject, including the United States Health Insurance Portability and Accountability Act of 1996 ("HIPAA") if applicable. The Contributor hereby certifies that, if the patient consent form is in a language other than English, such consent form meets all of the requirements set forth in the Instructions to Authors. In addition, the Contributor hereby confirms that he/she obtained from patient(s) written consent to use the patient identifiable content in both print and online (i.e., internet/web-based) publication formats. The Contributor further certifies that the person executing any such patient consent form, to the best of his/her knowledge, had legal capacity under applicable law to execute the form on behalf of the patient. 


\section{ACKNOWLEDGEMENTS}

The Contributor should obtain written permission from all individuals named in the acknowledgement since readers may infer their endorsement of data and conclusions. The Contributor certifies that all individuals named in the acknowledgement section have provided written permission to be named.

\section{J. MISCELLANEOUS}

This Agreement may be amended or modified only in a writing executed by both parties. The waiver or failure of any party to exercise any rights under this Agreement shall not be deemed a waiver or other limitation of any other right or any future right. This Agreement shall inure to the benefit of, and shall be binding upon, the parties, their respective successors and permitted assigns. This Agreement may be executed in two (2) or more counterparts, each of which shall be an original and all of which taken together shall constitute one and the same agreement. Executed copies of this Agreement may be delivered by facsimile transmission, pdf/email or other comparable electronic means. If for any reason any provision of this Agreement shall be deemed by a court of competent jurisdiction to be legally invalid or unenforceable, the validity, legality and enforceability of the remainder of this Agreement shall not be affected and such provision shall be deemed modified to the minimum extent necessary to make such provision consistent with applicable law and, in its modified form, such provision shall then be enforceable and enforced. The parties agree to do such further acts and to execute and deliver such additional agreements and instruments from time to time as either may at any time reasonably request in order to assure and confirm unto such requesting party the rights, powers and remedies conferred in the Agreement. This Agreement, including any exhibits attached hereto, contains the entire agreement and understanding of the parties with respect to the subject matter hereof, and supersedes all prior agreements, negotiations, representations and proposals, written and oral, relating thereto.

\section{All Contributors must sign below. Contributors must check one box except that NIH grantees should check both Contributor-owned work and the NIH grantee box. If your Contribution was written during the course of employment, your employer must also sign where indicated.}

Please send your original completed and signed forms by fax or email a scanned copy to the Journal production editor. For production editor contact details please visit the Journal's online author guidelines. Do not send in hard copies of these forms.

] Contributor-owned work Praveen Dayalu MD, Associate Professor in Neurology
Type or print name and title

Co-Contributor's signature Date

Type or print name and title 
] Company/Institution-owned

Work (made-for-hire in the

Course of employment)

Company or Institution (Employer-for-Hire)

Authorized signature of Employer

Date

Contributor's signature

Date

Type or print name and title

\section{ATTACH ADDITIONAL SIGNATURE PAGES AS NECESSARY}

\section{[__ ] U.S. Government work}

Note to U.S. Government Employees

A contribution prepared by a U.S. federal government employee as part of the employee's official duties, or which is an official U.S. Government publication, is called a "U.S. Government work", and is in the public domain in the United States. In such case, Paragraph A.1 will not apply but the Contributor must type his/her name (in the Contributor's signature line) above. Contributor acknowledges that the Contribution will be published in the United States and other countries. If the Contribution was not prepared as part of the employee's duties or is not an official U.S. Government publication, it is not a U.S. Government work.

\section{[__ ] U.K. Government work (Crown Copyright)}

Note to U.K. Government Employees

The rights in a contribution prepared by an employee of a UK government department, agency or other Crown body as part of his/her official duties, or which is an official government publication, belong to the Crown. Contributors must ensure they comply with departmental regulations and submit the appropriate authorisation to publish. If your status as a government employee legally prevents you from signing this Agreement, please contact the Journal production editor.

\section{[__ Other}

Including Other Government work or Non-Governmental Organisation work Note to Non-U.S., Non-U.K. Government Employees or Non-Governmental Organisation Employees If your status as a government or non-governmental organisation employee legally prevents you from signing this Agreement, please contact the Journal production editor. 


\section{$\underline{\text { Exhibit A }}$}

\section{Financial Disclosure}

The Contributor has received financial and material support for this research and work regardless of date from the following sources:

Name:

Address:

Type of support:

This material will be printed with the published article.

In the past year from the date of submission, the Contributor has also received the following support unrelated to this research (e.g., grants, advisory boards, employment, consultancies, contracts, honoraria, royalties, expert testimony, partnerships, or stock ownership in medically-related fields):

Name: Vaccinex

Address: 1895 Mt Hope Ave, Rochester, NY 14620

Type of support: Clinical trials grant

This material will be posted on the journal website and may be printed at the Editors' discretion.

\section{ATTACH ADDITIONAL INFORMATION AS NECESSARY}

This article is protected by copyright. All rights reserved. 


\section{COPYRIGHT TRANSFER AGREEMENT}

Date: April 1, 2019

Contributor name: DAVIO CELLA

Contributor address: 633 N. St. Clair, 19th flr, Chicago K 60011

Manuscript number: MDS - 19 - 0114.R1

HDQLIFE and Neuro-QoL Physical Function measures: Longitudinal validity in persons with Huntington disease (the "Contribution")

for publication in: Movement Disorders (the "Journal")

Published by Wiley on behalf of The International Parkinson and Movement Disorder Society (the "Owner")

Dear Contributor(s):

Thank you for submitting your Contribution for publication. In order to expedite the editing and publishing process and enable the Owner to disseminate your Contribution to the fullest extent, we need to have this Copyright Transfer Agreement executed. If the Contribution is not accepted for publication, or if the Contribution is subsequently rejected, this Agreement shall be null and void. Publication cannot proceed without a signed copy of this Agreement.

\section{A. COPYRIGHT}

The Contributor assigns to the Owner, during the full term of copyright and any extensions or renewals, all copyright in and to the Contribution, and all rights therein, including but not limited to the right to reproduce, publish, republish, transmit, sell, transfer, distribute, and otherwise use the Contribution in whole or in part in electronic and print editions of the Journal and in derivative works throughout the world, in all . languages and in all media of expression now known or later developed, and to license or permit others to do so.

\section{B. RETAINED RIGHTS}

Notwithstanding the above, the Contributor or, if applicable, the Contributor's employer, retains all proprietary rights other than copyright, such as patent rights, in any process, procedure or article of manufacture described in the Contribution. This reservation of rights does not affect or limit the rights assigned to Owner in Section A.

\section{PERMITTED USES BY CONTRIBUTOR}

1. License. The Owner grants to Contributor a non-exclusive, non-transferable and limited license to reproduce and distribute copies of the print or electronic "preprints" of the unpublished Contribution, in the original form submitted to the Journal prior to the peer review process, solely to colleagues within the Contributor's nonprofit organization or educational institution. The Contributor shall make no more than 100 printed copies of the preprints in any calendar year. Such preprints may be posted as electronic files on the Contributor's own personal website, on the Contributor's internal intranet at Contributor's nonprofit organization or educational institution, or on a secure external website at the Contributor's nonprofit organization or educational institution, provided that access is limited to employees and/or students at Contributor's non-profit organization or educational institution. Contributor shall not charge a fee for any 
preprints, and Contributor's use under this Section C shall not be for any commercial purpose, or for any systematic external distribution (e.g., posting on a listserve, public website, database connected to a public access server, or automated delivery system). The license grant in this Section does not apply to for-profit corporations, and any proposed use outside of the scope of this Section $\mathrm{C}$ must be pre-approved in writing by the Owner. The rights granted to Contributor under this Section $\mathrm{C}$ do not include reproduction, distribution or any other use of rating scales, videos or other audiovisual materials associated with the Contribution.

2. Required Citation. Prior to publication, the Contributor must provide full credit and acknowledgement of the Journal in all preprints in the following format: This is a preprint of an article accepted for publication in [Journal Title], Copyright $(\subset)$ [year] The International Parkinson and Movement Disorder Society. After publication, the Contributor must provide a citation to the Journal in all preprints in the following format: This is a preprint of an article that was published in [Journal title]: (Title of Article, Contributor, Journal Title and Volume/ Issue, Copyright $\mathbb{C}$ [year] The International Parkinson and Movement Disorder Society). An electronic link must be provided to the Journal's website, located at http://www.interscience.Wiley.com. The Contributor agrees not to update the preprint or replace it with the published version of the Contribution.

3. Accepted Version. Re-use of the accepted and peer-reviewed (but not the final typeset published) version of the Contribution (the "Accepted Version") is not permitted under this Agreement. There are separate arrangements with certain funding agencies governing reuse of the Accepted Version. Additional terms apply if the Contributor receives or received funding from these agencies. The details of those relationships, and other offerings allowing open web use, are set forth at the following website: http://www.wiley.com/go/ funderstatement.

4. Additional Terms for Certain Funders. Certain funders, including the NIH, members of the Research Councils UK (RCUK) and Wellcome Trust require deposit of the Accepted Version in a public repository after an embargo period. Details of funding arrangements are set out at the following website:

http://www.wiley.com/go/funderstatement. Additional terms may be applicable. Please contact the production editor for the journal at MDSprod@wiley.com if you have additional funding requirements.

If any Contributor receiving funds from applicable sources does not choose the Owner's OnlineOpen option, the Contributor will be allowed to self-archive by depositing the Accepted Version in a public repository after the following applicable embargo period has expired, subject to further conditions imposed by the RCUK:

a. $\quad 12$ months from first publication online of the final published version of the Contribution for research funded by members of the Research Councils UK (RCUK) other than The Economic and Social Research Council (ESRC) and the Arts and Humanities Research Council (AHRC); or

b. 24 months from first publication online of the final published version of the Contribution for research funded by ESRC or AHRC.

5. Additional Terms for Certain Institutions. Wiley has arrangements with certain educational institutions to permit the deposit of the Accepted Version in the institutional repository after an embargo period. Details of such arrangements are set out at the following website: http://olabout.wiley.com/WileyCDA/Section/id-406074.html . Additional terms may be applicable.

If any Contributor affiliated with these applicable educational institutions does not choose the Owner's OnlineOpen option, the Contributor will be allowed to self-archive by depositing the Accepted Version in the educational institution's repository after the following applicable embargo period has expired. See the following website for details: http://olabout.wiley.com/WileyCDA/Section/id-817011.html. 


\section{CONTRIBUTIONS OWNED BY EMPLOYER}

If the Contribution was written by the Contributor in the course of the Contributor's employment (as a "work-made-for-hire" in the course of employment), the Contribution is owned by the company/institution which must execute this Agreement (in addition to the Contributor's signature). In such case, the company/institution hereby assigns to the Owner, during the full term of copyright, all copyright in and to the Contribution for the full term of copyright throughout the world as specified in Section A above.

\section{E. GOVERNMENT CONTRACTS}

In the case of a Contribution prepared under U.S. Government contract or grant, the U.S. Government may reproduce, without charge, all or portions of the Contribution and may authorize others to do so, for official U.S. Government purposes only, if the U.S. Government contract or grant so requires. (U.S. Government, U.K. Government, and other government employees: see notes at end.)

\section{F. CONTRIBUTOR'S REPRESENTATIONS}

The Contributor represents that the Contribution is the Contributor's original work, all individuals identified as Contributors actually contributed to the Contribution, and all individuals who contributed are included. The Contribution is submitted only to this Journal and has not been published before. (If excerpts from copyrighted works owned by third parties are included, the Contributor will obtain written permission from the copyright owners for all uses as set forth in the Journal's Instructions for Contributors, and show credit to the sources in the Contribution.) The Contributor also warrants that the Contribution contains no libelous or unlawful statements, does not infringe upon the rights (including without limitation the copyright, patent or trademark rights) or the privacy of others, or contain material or instructions that might cause harm or injury. Upon request, Contributor will provide the data or will cooperating fully in obtaining and providing the data on which the Contribution is based for examination by the editors or their assignees.

\section{G. FINANCIAL DISCLOSURES}

The Contributor certifies that his/her financial and material support for this research and work, regardless of date, is clearly identified on Exhibit A to this Agreement. The Contributor has also identified on Exhibit A, all other support unrelated to this research, covering the past year from the date of submission (e.g., grants, advisory boards, employment, consultancies, contracts, honoraria, royalties, expert testimony, partnerships, or stock ownership in medically-related fields).

\section{H. VIDEO AND PHOTOGRAPHY CONSENT}

In the event that the Contribution includes, discloses or incorporates any content (including, without limitation, any video clip or photograph) which identifies any individual patient(s) ("patient identifiable content"), the Contributor obtained from such patient(s) written consent to such inclusion, disclosure or incorporation and that this consent fully complies with all legal requirements, including without limitation, all of the requirements of the laws of the jurisdiction(s) to which the patient(s) and the patient(s)' physician are subject, including the United States Health Insurance Portability and Accountability Act of 1996 ("HIPAA") if applicable. The Contributor hereby certifies that, if the patient consent form is in a language other than English, such consent form meets all of the requirements set forth in the Instructions to Authors. In addition, the Contributor hereby confirms that he/she obtained from patient(s) written consent to use the patient identifiable content in both print and online (i.e., internet/web-based) publication formats. The Contributor further certifies that the person executing any such patient consent form, to the best of his/her knowledge, had legal capacity under applicable law to execute the form on behalf of the patient. 


\section{ACKNOWLEDGEMENTS}

The Contributor should obtain written permission from all individuals named in the acknowledgement since readers may infer their endorsement of data and conclusions. The Contributor certifies that all individuals named in the acknowledgement section have provided written permission to be named.

\section{J. MISCELLANEOUS}

This Agreement may be amended or modified only in a writing executed by both parties. The waiver or failure of any party to exercise any rights under this Agreement shall not be deemed a waiver or other limitation of any other right or any future right. This Agreement shall inure to the benefit of, and shall be binding upon, the parties, their respective successors and permitted assigns. This Agreement may be executed in two (2) or more counterparts, each of which shall be an original and all of which taken together shall constitute one and the same agreement. Executed copies of this Agreement may be delivered by facsimile transmission, pdf/email or other comparable electronic means. If for any reason any provision of this Agreement shall be deemed by a court of competent jurisdiction to be legally invalid or unenforceable, the validity, legality and enforceability of the remainder of this Agreement shall not be affected and such provision shall be deemed modified to the minimum extent necessary to make such provision consistent with applicable law and, in its modified form, such provision shall then be enforceable and enforced. The parties agree to do such further acts and to execute and deliver such additional agreements and instruments from time to time as either may at any time reasonably request in order to assure and confirm unto such requesting party the rights, powers and remedies conferred in the Agreement. This Agreement, including any exhibits attached hereto, contains the entire agreement and understanding of the parties with respect to the subject matter hereof, and supersedes all prior agreements, negotiations, representations and proposals, written and oral, relating thereto.

All Contributors must sign below. Contributors must check one box except that NIH grantees should check both Contributor-owned work and the NIH grantee box. If your Contribution was written during the course of employment, your employer must also sign where indicated.

Please send your original completed and signed forms by fax or email a scanned copy to the Journal production editor. For production editor contact details please visit the Journal's online author guidelines. Do not send in hard copies of these forms.

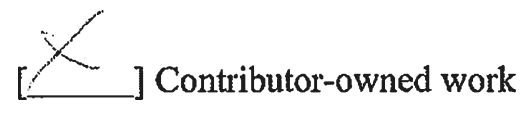

$$
\text { Contributor's signature }
$$

Date

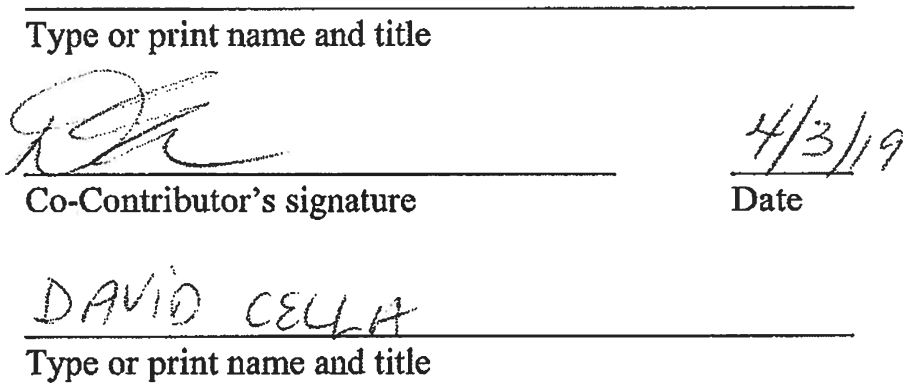

This article is protected by copyright. All rights reserved. 
] Company/Institution-owned Work (made-for-hire in the Course of employment)

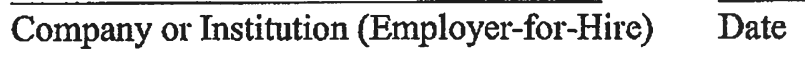

Authorized signature of Employer

Contributor's signature

Date

Type or print name and title

\section{ATTACH ADDITIONAL SIGNATURE PAGES AS NECESSARY}

\section{[_] U.S. Government work}

Note to U.S. Government Employees

A contribution prepared by a U.S. federal government employee as part of the employee's official duties, or which is an official U.S. Government publication, is called a "U.S. Government work", and is in the public domain in the United States. In such case, Paragraph A.1 will not apply but the Contributor must type his/her name (in the Contributor's signature line) above. Contributor acknowledges that the Contribution will be published in the United States and other countries. If the Contribution was not prepared as part of the employee's duties or is not an official U.S. Government publication, it is not a U.S. Government work.

\section{[_ ] U.K. Government work (Crown Copyright)}

Note to U.K. Government Employees

The rights in a contribution prepared by an employee of a UK government department, agency or other Crown body as part of his/her official duties, or which is an official government publication, belong to the Crown. Contributors must ensure they comply with departmental regulations and submit the appropriate authorisation to publish. If your status as a government employee legally prevents you from signing this Agreement, please contact the Journal production editor:

\section{[_] Other}

Including Other Government work or Non-Governmental Organisation work Note to Non-U.S., Non-U.K. Government Einployees or Non-Governmental Organisation Employees If your status as a government or non-governmental organisation employee legally prevents you from signing this Agreement, please contact the Journal production editor. 


\section{Exhibit A}

\section{Financial Disclosure}

The Contributor has received financial and material support for this research and work regardless of date from the following sources:

Name: DAVID CELLA

Address: Northuestern U.

Type of support: grant NeuvQ QuL HHSN 2652004236 OKC

This material will be printed with the published article.

In the past year from the date of submission, the Contributor has also received the following support unrelated to this research (e.g., grants, advisory boards, employment, consultancies, contracts, honoraria, royalties, expert testimony, partnerships, or stock ownership in medically-related fields):

Name:

Address:

Type of support:

This material will be posted on the journal website and may be printed at the Editors' discretion.

\section{ATTACH ADDITIONAL INFORMATION AS NECESSARY}

This article is protected by copyright. All rights reserved. 
Date: April 1, 2019

Contributor name:

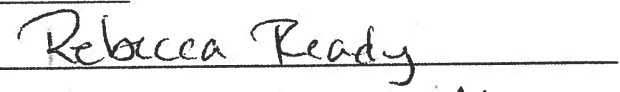

contributor address: 135 Hicks way, Uhass, Ammerst MA O1002

Manuscript number: MDS - 19-0114.R1

HDQLIFE and Neuro-QoL Physical Function measures:

Re: Manuscript entitled: Longitudinal validity in persons with Huntington disease (the "Contribution")

for publication in: Movement Disorders (the "Journal")

Published by Wiley on behalf of The International Parkinson and Movement Disorder Society (the "Owner")

Dear Contributor(s):

Thank you for submitting your Contribution for publication. In order to expedite the editing and publishing process and enable the Owner to disseminate your Contribution to the fullest extent, we need to have this Copyright Transfer Agreement executed. If the Contribution is not accepted for publication, or if the Contribution is subsequently rejected, this Agreement shall be null and void. Publication cannot proceed without a signed copy of this Agreement.

\section{A. COPYRIGHT}

The Contributor assigns to the Owner, during the full term of copyright and any extensions or renewals, all copyright in and to the Contribution, and all rights therein, including but not limited to the right to reproduce, publish, republish, transmit, sell, transfer, distribute, and otherwise use the Contribution in whole or in part in electronic and print editions of the Journal and in derivative works throughout the world, in all languages and in all media of expression now known or later developed, and to license or permit others to do so.

\section{B. RETAINED RIGHTS}

Notwithstanding the above, the Contributor or, if applicable, the Contributor's employer, retains all proprietary rights other than copyright, such as patent rights, in any process, procedure or article of manufacture described in the Contribution. This reservation of rights does not affect or limit the rights assigned to Owner in Section A.

\section{PERMITTED USES BY CONTRIBUTOR}

1. License. The Owner grants to Contributor a non-exclusive, non-transferable and limited license to reproduce and distribute copies of the print or electronic "preprints" of the unpublished Contribution, in the original form submitted to the Journal prior to the peer review process, solely to colleagues within the Contributor's nonprofit organization or educational institution. The Contributor shall make no more than 100 printed copies of the preprints in any calendar year. Such preprints may be posted as electronic files on the Contributor's own personal website, on the Contributor's internal intranet at Contributor's nonprofit organization or educational institution, or on a secure external website at the Contributor's nonprofit organization or educational institution, provided that access is limited to employees and/or students at Contributor's non-profit organization or educational institution. Contributor shall not charge a fee for any 
preprints, and Contributor's use under this Section C shall not be for any commercial purpose, or for any systematic external distribution (e.g., posting on a listserve, public website, database connected to a public access server, or automated delivery system). The license grant in this Section does not apply to for-profit corporations, and any proposed use outside of the scope of this Section $\mathrm{C}$ must be pre-approved in writing by the Owner. The rights granted to Contributor under this Section $\mathrm{C}$ do not include reproduction, distribution or any other use of rating scales, videos or other audiovisual materials associated with the Contribution.

2. Required Citation. Prior to publication, the Contributor must provide full credit and acknowledgement of the Journal in all preprints in the following format: This is a preprint of an article accepted for publication in [Journal Title], Copyright $(\mathcal{C}$ [year] The International Parkinson and Movement Disorder Society. After publication, the Contributor must provide a citation to the Journal in all preprints in the following format: This is a preprint of an article that was published in [Journal title]: (Title of Article, Contributor, Journal Title and Volume/ Issue, Copyright (C) [year] The International Parkinson and Movement Disorder Society). An electronic link must be provided to the Journal's website, located at http://www.interscience. Wiley.com. The Contributor agrees not to update the preprint or replace it with the published version of the Contribution.

3. Accepted Version. Re-use of the accepted and peer-reviewed (but not the final typeset published) version of the Contribution (the "Accepted Version") is not permitted under this Agreement. There are separate arrangements with certain funding agencies governing reuse of the Accepted Version. Additional terms apply if the Contributor receives or received funding from these agencies. The details of those relationships, and other offerings allowing open web use, are set forth at the following website: http://www.wiley.com/go/ funderstatement.

4. Additional Terms for Certain Funders. Certain funders, including the NIH, members of the Research Councils UK (RCUK) and Wellcome Trust require deposit of the Accepted Version in a public repository after an embargo period. Details of funding arrangements are set out at the following website: http://www.wiley.com/go/funderstatement. Additional terms may be applicable. Please contact the production editor for the journal at MDSprod@wiley.com if you have additional funding requirements.

If any Contributor receiving funds from applicable sources does not choose the Owner's OnlineOpen option, the Contributor will be allowed to self-archive by depositing the Accepted Version in a public repository after the following applicable embargo period has expired, subject to further conditions imposed by the RCUK:

a. $\quad 12$ months from first publication online of the final published version of the Contribution for research funded by members of the Research Councils UK (RCUK) other than The Economic and Social Research Council (ESRC) and the Arts and Humanities Research Council (AHRC); or

b. $\quad 24$ months from first publication online of the final published version of the Contribution for research funded by ESRC or AHRC.

5. Additional Terms for Certain Institutions. Wiley has arrangements with certain educational institutions to permit the deposit of the Accepted Version in the institutional repository after an embargo period. Details of such arrangements are set out at the following website: http://olabout.wiley.com/WileyCDA/Section/id-406074.html . Additional terms may be applicable.

If any Contributor affiliated with these applicable educational institutions does not choose the Owner's OnlineOpen option, the Contributor will be allowed to self-archive by depositing the Accepted Version in the educational institution's repository after the following applicable embargo period has expired. See the following website for details: http://olabout.wiley.com/WileyCDA/Section/id-817011.html. 


\section{CONTRIBUTIONS OWNED BY EMPLOYER}

If the Contribution was written by the Contributor in the course of the Contributor's employment (as a "work-made-for-hire" in the course of employment), the Contribution is owned by the company/institution which must execute this Agreement (in addition to the Contributor's signature). In such case, the company/institution hereby assigns to the Owner, during the full term of copyright, all copyright in and to the Contribution for the full term of copyright throughout the world as specified in Section A above.

\section{E. GOVERNMENT CONTRACTS}

In the case of a Contribution prepared under U.S. Government contract or grant, the U.S. Government may reproduce, without charge, all or portions of the Contribution and may authorize others to do so, for official U.S. Government purposes only, if the U.S. Government contract or grant so requires. (U.S. Government, U.K. Government, and other government employees: see notes at end.)

\section{F. CONTRIBUTOR'S REPRESENTATIONS}

The Contributor represents that the Contribution is the Contributor's original work, all individuals identified as Contributors actually contributed to the Contribution, and all individuals who contributed are included. The Contribution is submitted only to this Journal and has not been published before. (If excerpts from copyrighted works owned by third parties are included, the Contributor will obtain written permission from the copyright owners for all uses as set forth in the Journal's Instructions for Contributors, and show credit to the sources in the Contribution.) The Contributor also warrants that the Contribution contains no libelous or unlawful statements, does not infringe upon the rights (including without limitation the copyright, patent or trademark rights) or the privacy of others, or contain material or instructions that might cause harm or injury. Upon request, Contributor will provide the data or will cooperating fully in obtaining and providing the data on which the Contribution is based for examination by the editors or their assignees.

\section{G. FINANCIAL DISCLOSURES}

The Contributor certifies that his/her financial and material support for this research and work, regardless of date, is clearly identified on Exhibit A to this Agreement. The Contributor has also identified on Exhibit A, all other support unrelated to this research, covering the past year from the date of submission (e.g., grants, advisory boards, employment, consultancies, contracts, honoraria, royalties, expert testimony, partnerships, or stock ownership in medically-related fields).

\section{H. VIDEO AND PHOTOGRAPHY CONSENT}

In the event that the Contribution includes, discloses or incorporates any content (including, without limitation, any video clip or photograph) which identifies any individual patient(s) ("patient identifiable content"), the Contributor obtained from such patient(s) written consent to such inclusion, disclosure or incorporation and that this consent fully complies with all legal requirements, including without limitation, all of the requirements of the laws of the jurisdiction(s) to which the patient(s) and the patient(s)' physician are subject, including the United States Health Insurance Portability and Accountability Act of 1996 ("HIPAA") if applicable. The Contributor hereby certifies that, if the patient consent form is in a language other than English, such consent form meets all of the requirements set forth in the Instructions to Authors. In addition, the Contributor hereby confirms that he/she obtained from patient(s) written consent to use the patient identifiable content in both print and online (i.e., internet/web-based) publication formats. The Contributor further certifies that the person executing any such patient consent form, to the best of his/her knowledge, had legal capacity under applicable law to execute the form on behalf of the patient. 


\section{ACKNOWLEDGEMENTS}

The Contributor should obtain written permission from all individuals named in the acknowledgement since readers may infer their endorsement of data and conclusions. The Contributor certifies that all individuals named in the acknowledgement section have provided written permission to be named.

\section{J. MISCELLANEOUS}

This Agreement may be amended or modified only in a writing executed by both parties. The waiver or failure of any party to exercise any rights under this Agreement shall not be deemed a waiver or other limitation of any other right or any future right. This Agreement shall inure to the benefit of, and shall be binding upon, the parties, their respective successors and permitted assigns. This Agreement may be executed in two (2) or more counterparts, each of which shall be an original and all of which taken together shall constitute one and the same agreement. Executed copies of this Agreement may be delivered by facsimile transmission, pdf/email or other comparable electronic means. If for any reason any provision of this Agreement shall be deemed by a court of competent jurisdiction to be legally invalid or unenforceable, the validity, legality and enforceability of the remainder of this Agreement shall not be affected and such provision shall be deemed modified to the minimum extent necessary to make such provision consistent with applicable law and, in its modified form, such provision shall then be enforceable and enforced. The parties agree to do such further acts and to execute and deliver such additional agreements and instruments from time to time as either may at any time reasonably request in order to assure and confirm unto such requesting party the rights, powers and remedies conferred in the Agreement. This Agreement, including any exhibits attached hereto, contains the entire agreement and understanding of the parties with respect to the subject matter hereof, and supersedes all prior agreements, negotiations, representations and proposals, written and oral, relating thereto.

All Contributors must sign below. Contributors must check one box except that NIH grantees should check both Contributor-owned work and the NIH grantee box. If your Contribution was written during the course of employment, your employer must also sign where indicated.

Please send your original completed and signed forms by fax or email a scanned copy to the Journal production editor. For production editor contact details please visit the Journal's online author guidelines. Do not send in hard copies of these forms.

$[$ ] Contributor-owned work

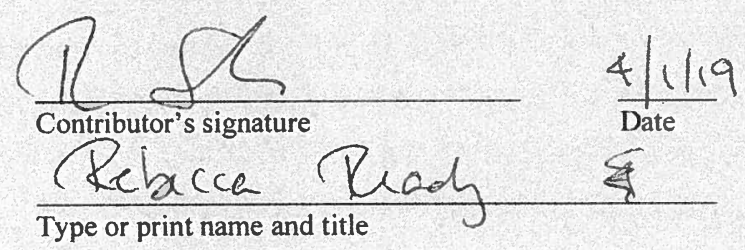

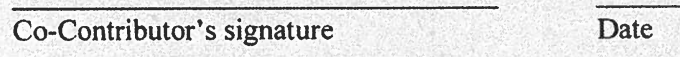

Type or print name and title 
] Company/Institution-owned Work (made-for-hire in the Course of employment)

\begin{tabular}{ll}
\hline Company or Institution (Employer-for-Hire) & $\overline{\text { Date }}$ \\
\hline Authorized signature of Employer & $\overline{\text { Date }}$ \\
\hline Contributor's signature & $\overline{\text { Date }}$
\end{tabular}

Type or print name and title

ATTACH ADDITIONAL SIGNATURE PAGES AS NECESSARY

\section{[ ] U.S. Government work}

Note to U.S. Government Employees

A contribution prepared by a U.S. federal government employee as part of the employee's official duties, or which is an official U.S. Government publication, is called a "U.S. Government work", and is in the public domain in the United States. In such case, Paragraph A.l will not apply but the Contributor must type his/her name (in the Contributor's signature line) above. Contributor acknowledges that the Contribution will be published in the United States and other countries. If the Contribution was not prepared as part of the employee's duties or is not an official U.S. Government publication, it is not a U.S. Government work.

\section{[_] ] U.K. Government work (Crown Copyright)}

Note to U.K. Government Employees

The rights in a contribution prepared by an employee of a UK government department, agency or other Crown body as part of his/her official duties, or which is an official government publication, belong to the Crown. Contributors must ensure they comply with departmental regulations and submit the appropriate authorisation to publish. If your status as a government employee legally prevents you from signing this Agreement, please contact the Journal production editor.

\section{[_] Other}

Including Other Government work or Non-Governmental Organisation work Note to Non-U.S., Non-U.K. Government Employees or Non-Governmental Organisation Employees If your status as a government or non-governmental organisation employee legally prevents you from signing this Agreement, please contact the Journal production editor.

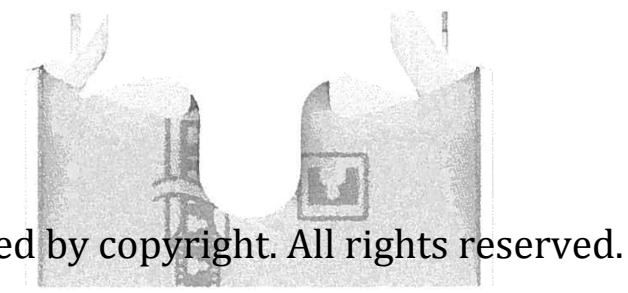




\section{Exhibit A}

\section{Financial Disclosure}

The Contributor has received financial and material support for this research and work regardless of date from the following sources: $\quad \cup \mid A$

Name:

Address:

Type of support:

This material will be printed with the published article.

In the past year from the date of submission, the Contributor has also received the following support unrelated to this research (e.g., grants, advisory boards, employment, consultancies, contracts, honoraria, royalties, expert testimony, partnerships, or stock ownership in medically-related fields):

N $A$

Name:

Address:

Type of support:

This material will be posted on the journal website and may be printed at the Editors' discretion.

\section{ATTACH ADDITIONAL INFORMATION AS NECESSARY}

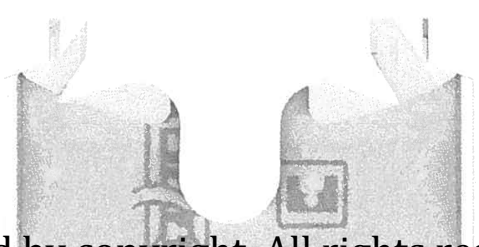

This article is protected by copyright. All rights reserved. 


\section{COPYRIGHT TRANSFER AGREEMENT}

Date: $411 / 2019$

Contributor name: NOELle E. CAR COZZ1

Contributor address: 2800 PLYMOVTH RO, ANN ARBon MI 48109

Manuscript number: MDS-19-OII4.RI

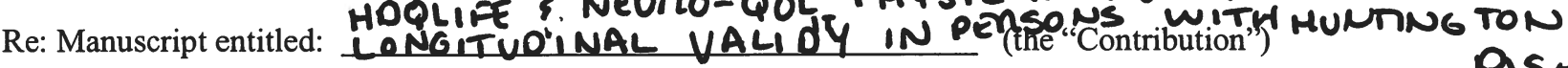

for publication in: Movement Disorders (the "Journal")

Published by Wiley on behalf of The International Parkinson and Movement Disorder Society (the

"Owner")

Dear Contributor(s):

Thank you for submitting your Contribution for publication. In order to expedite the editing and publishing process and enable the Owner to disseminate your Contribution to the fullest extent, we need to have this Copyright Transfer Agreement executed. If the Contribution is not accepted for publication, or if the Contribution is subsequently rejected, this Agreement shall be null and void. Publication cannot proceed without a signed copy of this Agreement.

\section{A. COPYRIGHT}

The Contributor assigns to the Owner, during the full term of copyright and any extensions or renewals, all copyright in and to the Contribution, and all rights therein, including but not limited to the right to reproduce, publish, republish, transmit, sell, transfer, distribute, and otherwise use the Contribution in whole or in part in electronic and print editions of the Journal and in derivative works throughout the world, in all languages and in all media of expression now known or later developed, and to license or permit others to do so.

\section{B. RETAINED RIGHTS}

Notwithstanding the above, the Contributor or, if applicable, the Contributor's employer, retains all proprietary rights other than copyright, such as patent rights, in any process, procedure or article of manufacture described in the Contribution. This reservation of rights does not affect or limit the rights assigned to Owner in Section A.

\section{PERMITTED USES BY CONTRIBUTOR}

1. License. The Owner grants to Contributor a non-exclusive, non-transferable and limited license to reproduce and distribute copies of the print or electronic "preprints" of the unpublished Contribution, in the original form submitted to the Journal prior to the peer review process, solely to colleagues within the Contributor's nonprofit organization or educational institution. The Contributor shall make no more than 100 printed copies of the preprints in any calendar year. Such preprints may be posted as electronic files on the Contributor's own personal website, on the Contributor's internal intranet at Contributor's nonprofit organization or educational institution, or on a secure external website at the Contributor's nonprofit organization or educational institution, provided that access is limited to employees and/or students at Contributor's non-profit organization or educational institution. Contributor shall not charge a fee for any 
preprints, and Contributor's use under this Section $\mathrm{C}$ shall not be for any commercial purpose, or for any systematic external distribution (e.g., posting on a listserve, public website, database connected to a public access server, or automated delivery system). The license grant in this Section does not apply to for-profit corporations, and any proposed use outside of the scope of this Section $\mathrm{C}$ must be pre-approved in writing by the Owner. The rights granted to Contributor under this Section $\mathrm{C}$ do not include reproduction, distribution or any other use of rating scales, videos or other audiovisual materials associated with the Contribution.

2. Required Citation. Prior to publication, the Contributor must provide full credit and acknowledgement of the Journal in all preprints in the following format: This is a preprint of an article accepted for publication in [Journal Title], Copyright $@$ [year] The International Parkinson and Movement Disorder Society. After publication, the Contributor must provide a citation to the Journal in all preprints in the following format: This is a preprint of an article that was published in [Journal title]: (Title of Article, Contributor, Journal Title and Volume/ Issue, Copyright $\mathbb{C}$ [year] The International Parkinson and Movement Disorder Society). An electronic link must be provided to the Journal's website, located at http://www.interscience.Wiley.com. The Contributor agrees not to update the preprint or replace it with the published version of the Contribution.

3. Accepted Version. Re-use of the accepted and peer-reviewed (but not the final typeset published) version of the Contribution (the "Accepted Version") is not permitted under this Agreement. There are separate arrangements with certain funding agencies governing reuse of the Accepted Version. Additional terms apply if the Contributor receives or received funding from these agencies. The details of those relationships, and other offerings allowing open web use, are set forth at the following website: http://www.wiley.com/go/ funderstatement.

4. Additional Terms for Certain Funders. Certain funders, including the NIH, members of the Research Councils UK (RCUK) and Wellcome Trust require deposit of the Accepted Version in a public repository after an embargo period. Details of funding arrangements are set out at the following website:

http:/www.wiley.com/go/funderstatement. Additional terms may be applicable. Please contact the production editor for the journal at MDSprod@wiley.com if you have additional funding requirements.

If any Contributor receiving funds from applicable sources does not choose the Owner's OnlineOpen option, the Contributor will be allowed to self-archive by depositing the Accepted Version in a public repository after the following applicable embargo period has expired, subject to further conditions imposed by the RCUK:

a. $\quad 12$ months from first publication online of the final published version of the Contribution for research funded by members of the Research Councils UK (RCUK) other than The Economic and Social Research Council (ESRC) and the Arts and Humanities Research Council (AHRC); or

b. $\quad 24$ months from first publication online of the final published version of the Contribution for research funded by ESRC or AHRC.

5. Additional Terms for Certain Institutions. Wiley has arrangements with certain educational institutions to permit the deposit of the Accepted Version in the institutional repository after an embargo period. Details of such arrangements are set out at the following website: http://olabout.wiley.com/WileyCDA/Section/id-406074.html . Additional terms may be applicable.

If any Contributor affiliated with these applicable educational institutions does not choose the Owner's OnlineOpen option, the Contributor will be allowed to self-archive by depositing the Accepted Version in the educational institution's repository after the following applicable embargo period has expired. See the following website for details: http://olabout.wiley.com/WileyCDA/Section/id-817011.html. 


\section{CONTRIBUTIONS OWNED BY EMPLOYER}

If the Contribution was written by the Contributor in the course of the Contributor's employment (as a "work-made-for-hire" in the course of employment), the Contribution is owned by the company/institution which must execute this Agreement (in addition to the Contributor's signature). In such case, the company/institution hereby assigns to the Owner, during the full term of copyright, all copyright in and to the Contribution for the full term of copyright throughout the world as specified in Section A above.

\section{E. GOVERNMENT CONTRACTS}

In the case of a Contribution prepared under U.S. Government contract or grant, the U.S. Government may reproduce, without charge, all or portions of the Contribution and may authorize others to do so, for official U.S. Government purposes only, if the U.S. Government contract or grant so requires. (U.S. Government, U.K. Government, and other government employees: see notes at end.)

\section{F. CONTRIBUTOR'S REPRESENTATIONS}

The Contributor represents that the Contribution is the Contributor's original work, all individuals identified as Contributors actually contributed to the Contribution, and all individuals who contributed are included. The Contribution is submitted only to this Journal and has not been published before. (If excerpts from copyrighted works owned by third parties are included, the Contributor will obtain written permission from the copyright owners for all uses as set forth in the Journal's Instructions for Contributors, and show credit to the sources in the Contribution.) The Contributor also warrants that the Contribution contains no libelous or unlawful statements, does not infringe upon the rights (including without limitation the copyright, patent or trademark rights) or the privacy of others, or contain material or instructions that might cause harm or injury. Upon request, Contributor will provide the data or will cooperating fully in obtaining and providing the data on which the Contribution is based for examination by the editors or their assignees.

\section{G. FINANCIAL DISCLOSURES}

The Contributor certifies that his/her financial and material support for this research and work, regardless of date, is clearly identified on Exhibit A to this Agreement. The Contributor has also identified on Exhibit A, all other support unrelated to this research, covering the past year from the date of submission (e.g., grants, advisory boards, employment, consultancies, contracts, honoraria, royalties, expert testimony, partnerships, or stock ownership in medically-related fields).

\section{H. VIDEO AND PHOTOGRAPHY CONSENT}

In the event that the Contribution includes, discloses or incorporates any content (including, without limitation, any video clip or photograph) which identifies any individual patient(s) ("patient identifiable content"), the Contributor obtained from such patient(s) written consent to such inclusion, disclosure or incorporation and that this consent fully complies with all legal requirements, including without limitation, all of the requirements of the laws of the jurisdiction(s) to which the patient(s) and the patient(s)' physician are subject, including the United States Health Insurance Portability and Accountability Act of 1996 ("HIPAA") if applicable. The Contributor hereby certifies that, if the patient consent form is in a language other than English, such consent form meets all of the requirements set forth in the Instructions to Authors. In addition, the Contributor hereby confirms that he/she obtained from patient(s) written consent to use the patient identifiable content in both print and online (i.e., internet/web-based) publication formats. The Contributor further certifies that the person executing any such patient consent form, to the best of his/her knowledge, had legal capacity under applicable law to execute the form on behalf of the patient. 


\section{ACKNOWLEDGEMENTS}

The Contributor should obtain written permission from all individuals named in the acknowledgement since readers may infer their endorsement of data and conclusions. The Contributor certifies that all individuals named in the acknowledgement section have provided written permission to be named.

\section{J. MiSCELLANEOUS}

This Agreement may be amended or modified only in a writing executed by both parties. The waiver or failure of any party to exercise any rights under this Agreement shall not be deemed a waiver or other limitation of any other right or any future right. This Agreement shall inure to the benefit of, and shall be binding upon, the parties, their respective successors and permitted assigns. This Agreement may be executed in two (2) or more counterparts, each of which shall be an original and all of which taken together shall constitute one and the same agreement. Executed copies of this Agreement may be delivered by facsimile transmission, pdf/email or other comparable electronic means. If for any reason any provision of this Agreement shall be deemed by a court of competent jurisdiction to be legally invalid or unenforceable, the validity, legality and enforceability of the remainder of this Agreement shall not be affected and such provision shall be deemed modified to the minimum extent necessary to make such provision consistent with applicable law and, in its modified form, such provision shall then be enforceable and enforced. The parties agree to do such further acts and to execute and deliver such additional agreements and instruments from time to time as either may at any time reasonably request in order to assure and confirm unto such requesting party the rights, powers and remedies conferred in the Agreement. This Agreement, including any exhibits attached hereto, contains the entire agreement and understanding of the parties with respect to the subject matter hereof, and supersedes all prior agreements, negotiations, representations and proposals, written and oral, relating thereto.

\section{All Contributors must sign below. Contributors must check one box except that NIH grantees should check both Contributor-owned work and the NIH grantee box. If your Contribution was written during the course of employment, your employer must also sign where indicated.}

Please send your original completed and signed forms by fax or email a scanned copy to the Journal production editor. For production editor contact details please visit the Journal's online author guidelines. Do not send in hard copies of these forms.
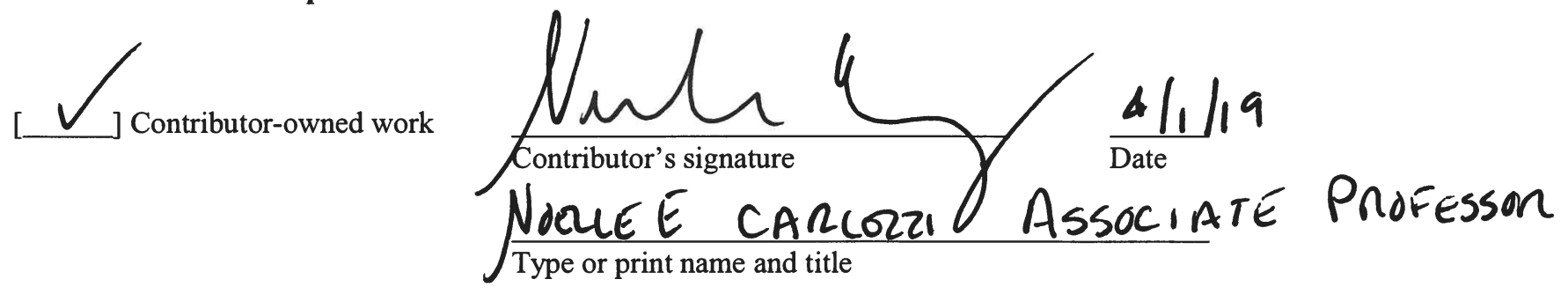
Co-Contributor's signature
Date

Type or print name and title 
] Company/Institution-owned Work (made-for-hire in the $\overline{\text { Company or Institution (Employer-for-Hire) }} \overline{\text { Date }}$ Course of employment)

Authorized signature of Employer

Contributor's signature

Type or print name and title
Date

Date

ATTACH ADDITIONAL SIGNATURE PAGES AS NECESSARY

\section{[__ ] U.S. Government work}

Note to U.S. Government Employees

A contribution prepared by a U.S. federal government employee as part of the employee's official duties, or which is an official U.S. Government publication, is called a "U.S. Government work", and is in the public domain in the United States. In such case, Paragraph A.1 will not apply but the Contributor must type his/her name (in the Contributor's signature line) above. Contributor acknowledges that the Contribution will be published in the United States and other countries. If the Contribution was not prepared as part of the employee's duties or is not an official U.S. Government publication, it is not a U.S. Government work.

\section{[__ U.K. Government work (Crown Copyright)}

Note to U.K. Government Employees

The rights in a contribution prepared by an employee of a UK government department, agency or other Crown body as part of his/her official duties, or which is an official government publication, belong to the Crown. Contributors must ensure they comply with departmental regulations and submit the appropriate authorisation to publish. If your status as a government employee legally prevents you from signing this Agreement, please contact the Journal production editor.

[_] Other

Including Other Government work or Non-Governmental Organisation work Note to Non-U.S., Non-U.K. Government Employees or Non-Governmental Organisation Employees If your status as a government or non-governmental organisation employee legally prevents you from signing this Agreement, please contact the Journal production editor. 
$\underline{\text { Exhibit A }}$

Financial Disclosure

The Contributor has received financial and material support for this research and work regardless of date from the following sources:

Name: NoEZle CarCOZZ

Address: 2800 PLYMOUTH RB. ANN ARBOR MI 48109

Type of support: $\mathrm{N} / \mathrm{H}$

This material will be printed with the published article.

In the past year from the date of submission, the Contributor has also received the following support unrelated to this research (e.g., grants, advisory boards, employment, consultancies, contracts, honoraria, royalties, expert testimony, partnerships, or stock ownership in medically-related fields):

Name:

Address:

Type of support:

This material will be posted on the journal website and may be printed at the Editors' discretion.

ATTACH ADDITIONAL INFORMATION AS NECESSARY

This article is protected by copyright. All rights reserved. 


\section{COPYRIGHT TRANSFER AGREEMENT}

Date: April 1, 2019

Contributor name:

michael KMCCormack, PhD, FAGMGG

Contributor address:

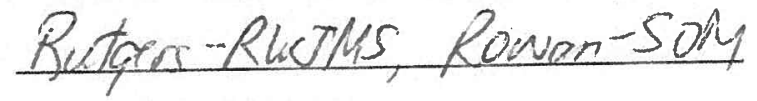

Manuscript number: MDS - 19-0114.R1

HDQLIFE and Neuro-QoL Physical Function measures:
Longitudinal validity in persons with Huntington disease

Re: Manuscript entitled:

(the "Contribution")

for publication in: Movement Disorders (the "Journal")

Published by Wiley on behalf of The International Parkinson and Movement Disorder Society (the "Owner")

Dear Contributor(s):

Thank you for submitting your Contribution for publication. In order to expedite the editing and publishing process and enable the Owner to disseminate your Contribution to the fullest extent, we need to have this Copyright Transfer Agreement executed. If the Contribution is not accepted for publication, or if the Contribution is subsequently rejected, this Agreement shall be null and void. Publication cannot proceed without a signed copy of this Agreement.

\section{A. COPYRIGHT}

The Contributor assigns to the Owner, during the full term of copyright and any extensions or renewals, all copyright in and to the Contribution, and all rights therein, including but not limited to the right to reproduce, publish, republish, transmit, sell, transfer, distribute, and otherwise use the Contribution in whole or in part in electronic and print editions of the Journal and in derivative works throughout the world, in all languages and in all media of expression now known or later developed, and to license or permit others to do so.

\section{B. RETAINED RIGHTS}

Notwithstanding the above, the Contributor or, if applicable, the Contributor's employer, retains all proprietary rights other than copyright, such as patent rights, in any process, procedure or article of manufacture described in the Contribution. This reservation of rights does not affect or limit the rights assigned to Owner in Section A.

\section{PERMITTED USES BY CONTRIBUTOR}

1. License. The Owner grants to Contributor a non-exclusive, non-transferable and limited license to reproduce and distribute copies of the print or electronic "preprints" of the unpublished Contribution, in the original form submitted to the Journal prior to the peer review process, solely to colleagues within the Contributor's nonprofit organization or educational institution. The Contributor shall make no more than 100 printed copies of the preprints in any calendar year. Such preprints may be posted as electronic files on the Contributor's own personal website, on the Contributor's internal intranet at Contributor's nonprofit organization or educational institution, or on a secure external website at the Contributor's nonprofit organization or educational institution, provided that access is limited to employees and/or students at Contributor's non-profit organization or educational institution. Contributor shall not charge a fee for any 
preprints, and Contributor's use under this Section $\mathrm{C}$ shall not be for any commercial purpose, or for any systematic external distribution (e.g., posting on a listserve, public website, database connected to a public access server, or automated delivery system). The license grant in this Section does not apply to for-profit corporations, and any proposed use outside of the scope of this Section C must be pre-approved in ivriting by the Owner. The rights granted to Contributor under this Section $\mathrm{C}$ do not include reproduction, distribution or any other use of rating scales, videos or other audiovisual materials associated with the Contribution.

2. Required Citation. Prior to publication, the Contributor must provide full credit and acknowledgement of the Journal in all preprints in the following format: This is a preprint of an article accepted for publication in [Journal Title], Copyright $(\mathcal{C}$ [year] The International Parkinson and Movement Disorder Society. After publication, the Contributor must provide a citation to the Journal in all preprints in the following format: This is a preprint of an article that was published in [Journal title]: (Title of Article, Contributor, Journal Title and Volume/ Issue, Copyright (C) [year] The International Parkinson and Movement Disorder Society). An electronic link must be provided to the Journal's website, located at hitp://www interscience. Wiley.com. The Contributor agrees not to update the preprint or replace it with the published version of the Contribution.

3. Accepted Version. Re-use of the accepted and peer-reviewed (but not the final typeset published) version of the Contribution (the "Accepted Version") is not permitted under this Agreement. There are separate arrangements with certain funding agencies governing reuse of the Accepted Version. Additional terms apply if the Contributor receives or received funding from these agencies. The details of those relationships, and other offerings allowing open web use, are set forth at the following website: http://www.wiley.com/go/ funderstatement.

4. Additional Terms for Certain Funders. Certain funders, including the NIH, members of the Research Councils UK (RCUK) and Wellcome Trust require deposit of the Accepted Version in a public repository after an embargo period. Details of funding arrangements are set out at the following website: http:/hww.wiles com/go/funderstatement. Additional terms may be applicable. Please contact the production editor for the journal at MDSprodswilcy.com if you have additional funding requirements.

If any Contibutu wuiving funds from applicable sources does not choose the Owner's Onlinennen nntinn the Contributor will be allowed to self-archive by depositing the Accepted Version in a public repository after the following applicable embargo period has expired, subject to further conditions imposed by the RCUK:

a.

12 months from first publication online of the final published version of the Contribution for research funded by members of the Research Councils UK (RCUK) other than The Economic and Social Research Council (ESRC) and the Arts and Humanities Research Council (AHRC); or

b. 24 months from first publication online of the final published version of the Contribution for research funded by ESRC or AHRC.

5. Additional Terms for Certain Institutions. Wiley has arrangements with certain educational institutions to permit the deposit of the Accepted Version in the institutional repository after an embargo period. Details of such arrangements are set out at the following website: http://olabout wiley com/WileyCDA/Section/id-406074.htm/. Additional terms may be applicable.

If any Contributor affiliated with these applicable educational institutions does not choose the Owner's OnlineOpen option, the Contributor will be allowed to self-archive by depositing the Accepted Version in the educational institution's repository after the following applicable embargo period has expired. See the following website for details: hitp://olabout wiles com/WilerCDA/Section/id-817011/html. 


\section{CONTRIBUTIONS OWNED BY EMPLOYER}

If the Contribution was written by the Contributor in the course of the Contributor's employment (as a "work-made-for-hire" in the course of employment), the Contribution is owned by the company/institution which must execute this Agreement (in addition to the Contributor's signature). In such case, the company/institution hereby assigns to the Owner, during the full term of copyright, all copyright in and to the Contribution for the full term of copyright throughout the world as specified in Section A above.

\section{E. GOVERNMENT CONTRACTS}

In the case of a Contribution prepared under U.S. Government contract or grant, the U.S. Government may reproduce, without charge, all or portions of the Contribution and may authorize others to do so, for official U.S. Government purposes only, if the U.S. Government contract or grant so requires. (U.S. Government, U.K. Government, and other government employees: see notes at end.)

\section{F. CONTRIBUTOR'S REPRESENTATIONS}

The Contributor represents that the Contribution is the Contributor's original work, all individuals identified as Contributors actually contributed to the Contribution, and all individuals who contributed are included. The Contribution is submitted only to this Journal and has not been published before. (If excerpts from copyrighted works owned by third parties are included, the Contributor will obtain written permission from the copyright owners for all uses as set forth in the Journal's Instructions for Contributors, and show credit to the sources in the Contribution.) The Contributor also warrants that the Contribution contains no libelous or unlawful statements, does not infringe upon the rights (including without limitation the copyright, patent or trademark rights) or the privacy of others, or contain material or instructions that might cause harm or injury. Upon request, Contributor will provide the data or will cooperating fully in obtaining and providing the data on which the Contribution is based for examination by the editors or their assignees.

\section{G. FINANCIAL DISCLOSURES}

The Contributor certifies that his/her financial and material support for this research and work, regardless of date, is clearly identified on Exhibit A to this Agreement. The Contributor has also identified on Exhibit A, all other support unrelated to this research, covering the past year from the date of submission (e.g., grants, advisory boards, employment, consultancies, contracts, honoraria, royalties, expert testimony, partnerships, or stock ownership in medically-related fields).

\section{H. VIDEO AND PHOTOGRAPHY CONSENT}

In the event that the Contribution includes, discloses or incorporates any content (including, without limitation, any video clip or photograph) which identifies any individual patient(s) ("patient identifiable content"), the Contributor obtained from such patient(s) written consent to such inclusion, disclosure or incorporation and that this consent fully complies with all legal requirements, including without limitation, all of the requirements of the laws of the jurisdiction(s) to which the patient(s) and the patient(s) ' physician are subject, including the United States Health Insurance Portability and Accountability Act of 1996 ("HIPAA") if applicable. The Contributor hereby certifies that, if the patient consent form is in a language other than English, such consent form meets all of the requirements set forth in the Instructions to Authors. In addition, the Contributor hereby confirms that he/she obtained from patient(s) written consent to use the patient identifiable content in both print and online (i.e., internet/web-based) publication formats. The Contributor further certifies that the person executing any such patient consent form, to the best of his/her knowledge, had legal capacity under applicable law to execute the form on behalf of the patient. 


\section{ACKNOWLEDGEMENTS}

The Contributor should obtain written permission from all individuals named in the acknowledgement since readers may infer their endorsement of data and conclusions. The Contributor certifies that all individuals named in the acknowledgement section have provided written permission to be named.

\section{J. MISCELLANEOUS}

This Agreement may be amended or modified only in a writing executed by both parties. The waiver or failure of any party to exercise any rights under this Agreement shall not be deemed a waiver or other limitation of any other right or any future right. This Agreement shall inure to the benefit of, and shall be binding upon, the parties, their respective successors and permitted assigns. This Agreement may be executed in two (2) or more counterparts, each of which shall be an original and all of which taken together shall constitute one and the same agreement. Executed copies of this Agreement may be delivered by facsimile transmission, pdf/email or other comparable electronic means. If for any reason any provision of this Agreement shall be deemed by a court of competent jurisdiction to be legally invalid or unenforceable, the validity, legality and enforceability of the remainder of this Agreement shall not be affected and such provision shall be deemed modified to the minimum extent necessary to make such provision consistent with applicable law and, in its modified form, such provision shall then be enforceable and enforced. The parties agree to do such further acts and to execute and deliver such additional agreements and instruments from time to time as either may at any time reasonably request in order to assure and confirm unto such requesting party the rights, powers and remedies conferred in the Agreement. This Agreement, including any exhibits attached hereto, contains the entire agreement and understanding of the parties with respect to the subject matter hereof, and supersedes all prior agreements, negotiations, representations and proposals, written and oral, relating thereto.

All Contributors must sign below. Contributors must check one box except that NIH grantees should check both Contributor-owned work and the NIH grantee box. If your Contribution was written during the course of employment, your employer must also sign where indicated.

Please send your original completed and signed forms by fax or email a scanned copy to the Journal production editnr. For nroduction editor contact details please visit the Journal's online author guidelines. Do not send in hard copies of these forms.

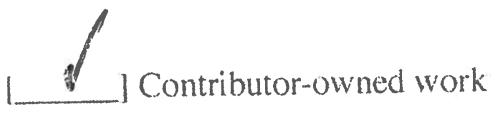

$$
\overline{\text { Contributor's signature }} \overline{\text { Date }}
$$

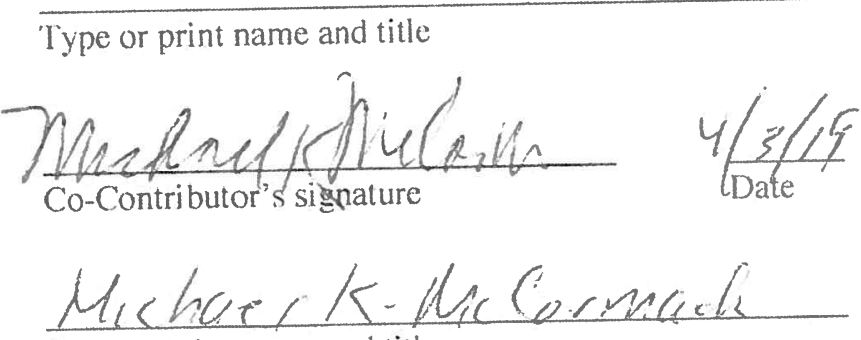

Type or print name and title 
[__ Company/Institution-owned

Work (made-for-hire in the

Company or Institution (Employer-for-Hire)

Date

Course of employment)

Authorized signature of Employer

Contributor's signature

Type or print name and title
Date

Date

\section{ATTACH ADDITIONAL SIGNATURE PAGES AS NECESSARY}

\section{I_ U.S. Government work}

Note to U.S. Government Employees

A contribution prepared by a US. federal government employee as part of the employee's official duties, or which is an official US. Government publication, is called a "U.S. Government work", and is in the public domain in the United States. In such case, Paragraph A.I will not apply but the Contributor must type his/her name (in the Contributor's signature line) above. Contributor acknowledges that the Contribution will be published in the United States and other countries. If the Contribution was not prepared as part of the employee's duties or is not an official U.S. Government publication, it is not a U.S. Government work.

\section{L_ ] U.K. Government work (Crown Copyright)}

Note to U.K. Government Employees

The rights in a contribution prepared by an employee of a UK government department, agency or other Crown body as part of his/her official duties, or which is an official government publication, belong to the Crown. Contributors must ensure they comply with departmental regulations and submit the appropriate authorisation to publish. If your status as a government employee legally prevents you from signing this Agreement, please contact the Journal production editor.

\section{I_ Other}

Including Other Government work or Non-Governmental Organisation work Note to Non-U.S., Non-U.K. Government Employees or Non-Governmental Organisation Employees If your status as a government or non-governmental organisation employee legally prevents you from signing this Agreement, please contact the Journal production editor. 


\section{Exhibit A}

\section{Financial Disclosure}

The Contributor has received financial and material support for this research and work regardless of date from the following sources:

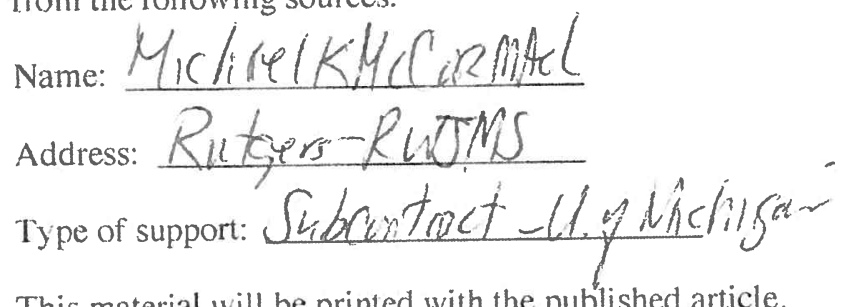

This material will be printed with the published article.

In the past year from the date of submission, the Contributor has also received the following support unrelated to this research (e.g., grants, advisory boards, employment, consultancies, contracts, honoraria, royalties, expert testimony, partnerships, or stock ownership in medically-related fields):

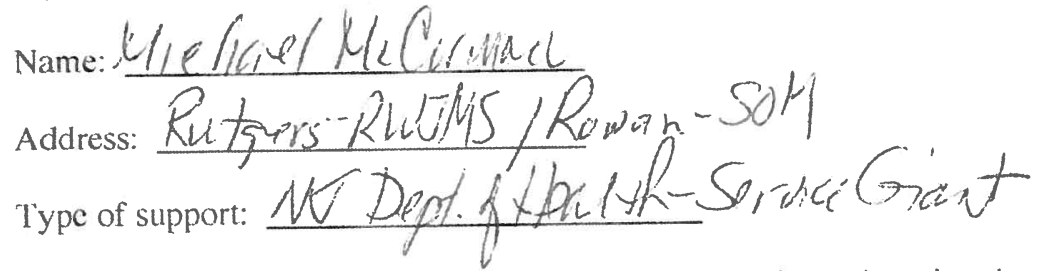

This material will be posted on the journal website and may be printed at the Editors' discretion.

\section{ATTACH ADIDITIONAL INFORMATION AS NECESSARY}

